\title{
A Density Functional Theory and Quantum Theory of Atoms-in-Molecules Analysis of the Stability of Ni(II) Complexes of Some Amino-Alcohol Ligands
}

\author{
Pradeep R.Varadwaj ${ }^{\mathrm{a}, \uparrow}$, Ignacy Cukrowski $^{\mathrm{a},{ }^{,},}$, Christopher B. Perry ${ }^{\mathrm{b}}$ \\ and Helder M. Marques ${ }^{\mathrm{b}, *}$
}

${ }^{a}$ Department of Chemistry, Faculty of Natural and Agricultural Sciences, University of Pretoria, Lynnwood Road, Hillcrest, Pretoria, 0002 South Africa; ${ }^{\mathrm{b}}$ Molecular Sciences Institute, School of Chemistry, University of the Witwatersrand, PO Wits, Johannesburg, 2050 South Africa

*Email: Ignacy.Cukrowski@up.ac.za; Helder.Marques@wits.ac.za

$\uparrow$ Department of Chemistry \& Biochemistry, Concordia University, 7141 Sherbrooke Street West, Montréal, Québec, Canada, H4B 1R6 


\section{Abstract}

The structure of the complexes of the type $\left[\mathrm{Ni}(\mathrm{L})\left(\mathrm{H}_{2} \mathrm{O}\right)_{2}\right]^{2+}$, where $\mathrm{L}$ is an amino-alcohol ligand, $\quad \mathrm{L}=N, N^{\prime}$-bis(2-hydroxyethyl)-ethane-1,2-diamine $\quad$ (BHEEN), $\quad N, N^{\prime}$-bis(2hydroxycyclohexyl)-ethane-1,2-diamine $\left(\mathrm{Cy}_{2} \mathrm{EN}\right)$ and $N, N^{\prime}$-bis(2-hydroxycyclopentyl)ethane-1,2-diamine, $\left(\mathrm{Cyp}_{2} \mathrm{EN}\right)$ were investigated at the X3LYP/6-31+G(d,p) level of theory both in the gas phase and in solvent (CPCM model) to gain insight into factors that control the experimental $\log K_{1}$ values. We find that (i) analyses based on Bader's quantum theory of atoms in molecules (QTAIM) are useful in providing significant insight into the nature of metal-ligand bonding and in clarifying the nature of weak "non-bonded" interactions in these complexes, and (ii) the conventional explanation of complex stability in these sorts of complexes (based on considerations of bond lengths, bite angles and H-clashes) could be inadequate and indeed might be misleading. The strength of metal-ligand bonds follows the order $\mathrm{Ni}-\mathrm{N}>\mathrm{Ni}-\mathrm{OH} \geq \mathrm{Ni}-\mathrm{OH}_{2}$; the bonds are predominantly ionic with some covalent character decreasing in the order $\mathrm{Ni}-\mathrm{N}>\mathrm{Ni}-\mathrm{OH}>\mathrm{Ni}-\mathrm{OH}_{2}$, with $\mathrm{Ni}-\mathrm{OH}_{2}$ being close to purely ionic. We predict that the cis complexes are preferred over the trans complexes because of (i) stronger bonding to the alcoholic O-donor atoms and (ii) more favorable intramolecular interactions, which appear to be important in determining the conformation of a metal-ligand complex. We show that (i) the flexibility of the ligand, which controls the $\mathrm{Ni}-\mathrm{OH}$ bond length, and (ii) the ability of the ligand to donate electron density to the metal are likely to be important factors in determining values of $\log K_{1}$. We find that the electron density at the ring critical point of the cyclopentyl moieties in $\mathrm{Cyp}_{2} \mathrm{EN}$ is much higher than that in the cyclohexyl moieties of $\mathrm{Cy}_{2} \mathrm{EN}$ and interpret this to mean that $\mathrm{Cyp}_{2} \mathrm{EN}$ is a poorer donor of electron density to a Lewis acid than $\mathrm{Cy}_{2} \mathrm{EN}$. 


\section{Introduction}

The measurement and prediction of the stability or formation constant, $K$, of a complex between a metal ion and a ligand in aqueous solution is an important aspect of coordination chemistry. ${ }^{1-9}$ Whilst many experimental methods exist for the determination of $K,{ }^{10,11}$ data may not always be easily obtained and it would clearly be useful if reliable predictive methods existed. There have been a number of approaches to this problem; ${ }^{12}$ probably the most common involves finding a correlation between $K$ and some measurable physical or chemical property, which can then be applied to novel systems or in a novel situation. ${ }^{12-23}$

Computational methods have been used in the estimation of stability constants. Empirical force field (molecular mechanics, MM) methods are often used as a way of rationalizing trends in stability constants, ${ }^{15,24,25}$ but the ability of these methods to predict them de novo is limited. Application of ab initio methods to transition metal systems is often difficult ${ }^{26}$ or requires very considerable computational resources. ${ }^{27}$ The development of DFT methods, and especially hybrid DFT methods - incorporating perhaps some reparameterization to properly treat spin state issues ${ }^{28}$ - has revolutionized the modeling of transition metal systems by computational methods. ${ }^{29,30}$

Hybrid functionals have been very successful in describing the bonding and the reactions of main group elements. ${ }^{31,32}$ However, because of their greater electronic complexity, modeling of transition metal complexes is more difficult and problems often arise that are sometimes only partly understood. ${ }^{31,33}$ For example, four-coordinate aqua$\mathrm{Zn}$ (II) ion is erroneously predicted to be more stable than the hexa-coordinate ion (attributed to an overestimation of the hard-soft interactions between the metal and the ligands ${ }^{34}$ ) and the geometries of trivalent first row $d$-block metal ions are often poorly reproduced. When modeling complexes of the first row transition series, it is not immediately obvious whether it is appropriate to compare the results of zero-temperature gas-phase DFT calculations to the condensed-phase finite-temperature experimental data which are typically available for the compounds of interest. ${ }^{35}$ The metals have a compact $d$ electron shell and a near-degeneracy of the $4 s$ and $3 d$ orbitals which results in strong electron correlation; it is therefore essential that electron correlation, and electron exchange, be treated adequately, ${ }^{31,35}$ and pure HartreeFock methods are inappropriate because of the neglect of electron correlation. Several spin states can occur for a number of electron configurations, controlled by the nature of metalligand bonding. Spin state energetics may not be well-handled and errors as high as $10 \mathrm{kcal}$ $\mathrm{mol}^{-1}$ are not unusual. ${ }^{35,36}$ DFT methods based on the generalized gradient approximation tend to favor low spin states, whilst HF methods are heavily biased to high spin states 
because of an imbalance between the Fermi and Coulomb correlation; ${ }^{36,37}$ hybrid functionals are therefore a good choice when examining spin state energetics. Unlike those of the heavier elements of the $d$ block, ${ }^{30}$ complexes of the first row transition series usually have insignificant relativistic effects. ${ }^{36}$ DFT methods reproduce geometries quite well, and are reasonably good for vibrational frequencies and total energies. ${ }^{36}$

Among the ligands we are interested in are the amino-alcohols. They are used in the pharmaceutical industry ${ }^{38-40}$ and as chiral reagents in organic syntheses; ${ }^{41-43}$ their complexes with $f$ block elements may well see their use in diagnostic and curative protocols in medicinal chemistry. ${ }^{44}$ When ethylene bridges between the donor $\mathrm{N}$ and $\mathrm{O}$ atoms in these aminoalcohol ligands are replaced by, for example, cyclohexyl bridges, the ligand that results has been termed reinforced. ${ }^{45}$ Reinforced ligands are of interest since it has been observed that whereas a 2-hydroxyethyl group promotes selectivity for larger metal ions relative to smaller metal ions, ${ }^{46}$ the presence of a cyclohexyl bridge between the $\mathrm{N}$ - and O-donor atoms reverses this trend and selectivity for smaller metal ions is promoted. Making the reasonable assumption that coordination to a small metal ion requires greater ligand curvature, the observation has been rationalized by envisaging that increasing the ligand curvature will diminish short non-bonded $\mathrm{CH} \cdots \mathrm{HC}$ contacts between $\mathrm{H}$ atoms (so-called H-clashes) on the cyclohexyl bridges and those on the ethylene bridges of the ligand. ${ }^{47,48}$

In some of our recent work on amino alcohols, we have reported the crystal structure of the nitrate salt of the commercially available ligand $N, N^{\prime}$-bis(2-hydroxyethyl)-ethane-1,2diamine (BHEEN, Figure 1), and its $\mathrm{Zn}(\mathrm{II})$ and $\mathrm{Cd}(\mathrm{II})$ complexes. ${ }^{49}$ In neither case are both hydroxyl arms coordinated to the metal: the $\mathrm{Zn}(\mathrm{II})$ complex crystallises as an $\mathrm{ML}_{2}$ species with the four $\mathrm{N}$-donors producing a distorted tetrahedral geometry around the metal and the hydroxyl groups forming a weak interaction (ca. $3 \AA$ ) with the metal, as determined from a QTAIM analysis $^{50}$ of the B3LYP/TZVP(Zn)/cc-pVTZ(H)/aug-cc-pVTZ(all other atoms) structure. The $\mathrm{Cd}(\mathrm{II})$ complex was a metal dimer with bridging chloride ligands and with only one hydroxyl group coordinated. However, MS-ESI of the solution showed multiple species, many of which are clearly monomeric with both hydroxyl groups coordinated to $\mathrm{Cd}(\mathrm{II})$.

The reaction of cyclohexene oxide with a diamine such as ethylenediamine produces mainly the meso form $(1 R, 2 R, 1 ' S, 2 ' S)$ of a product with two pendent cyclohexanol groups ( $N, N^{\prime}$-bis(2-hydroxycyclohexyl)-ethane-1,2-diamine $\left(\mathrm{Cy}_{2} \mathrm{EN}\right.$, Figure 1$) .{ }^{45,51}$ The equivalent cyclopentanol derivative ( $N, N^{\prime}$-bis(2-hydroxycyclopentyl)-ethane-1,2-diamine, $\left.\mathrm{Cyp}_{2} \mathrm{EN}\right)$ is produced from the reaction with cyclopentene oxide. ${ }^{52}$ The stability constants of these three 
ligands with a number of metal ions, including $\mathrm{Ni}(\mathrm{II})$, are available; the values $\left(\log K_{1}, 25^{\circ} \mathrm{C}, \mu=\right.$ $0.1 \mathrm{M}$ ) for the formation of NiL complexes are 7.77 for $\mathrm{L}=\mathrm{Cy}_{2} \mathrm{EN} ;{ }^{48} 6.67$ for $\mathrm{L}=\mathrm{BHEEN} ;{ }^{53,54}$ and 3.79 for $\mathrm{L}=\mathrm{Cyp}_{2} \mathrm{EN}^{55}$ If repulsive $\mathrm{CH} \cdots \mathrm{HC}$ interactions between the ethylenediamine backbone and the reinforcement rings are indeed important in controlling the affinity of these ligands for metal ions (vide supra), ${ }^{47,48}$ one might have expected the $\log K_{1}$ value for the coordination of $\mathrm{Ni}(\mathrm{II})$ by $\mathrm{Cyp}_{2} \mathrm{EN}$ to be larger (and not smaller) than that for coordination by $\mathrm{Cy}_{2} \mathrm{EN}$ as the $\mathrm{H} \cdots \mathrm{H}$ distances in question should decrease.

We have recently shown ${ }^{52}$ that the population-weighted root-mean square deviation

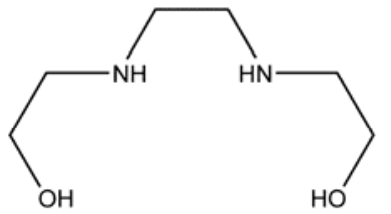

BHEEN
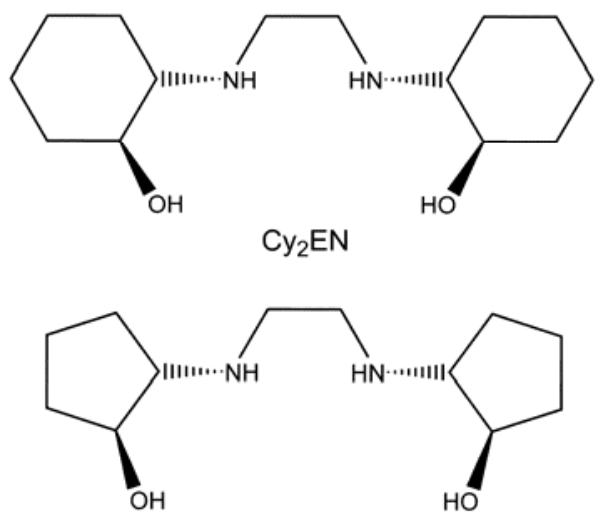

Cyp 2 EN

Figure 1. Three amino-alcohol ligands studied in this work. between the lowest energy conformers of these three ligands (discovered by conformational searching and $\mathrm{MM}$ ) and the likely conformation required for coordinating a metal ion increased in the order $\mathrm{Cy}_{2} \mathrm{EN}<\mathrm{Cyp}_{2} \mathrm{EN}<\mathrm{BHEEN}$, while formation constants for coordinating $\mathrm{Ni}(\mathrm{II})$ decrease in the order $\mathrm{Cy}_{2} \mathrm{EN}>\mathrm{BHEEN}>>$ $\mathrm{Cyp}_{2} \mathrm{EN}$; only $\mathrm{Cy}_{2} \mathrm{EN}$ is well pre-organized for coordinating a metal ion due to formation of an intramolecular $\mathrm{NH}-\mathrm{O}$ hydrogen bond. So, while pre-organization may be an important factor in controlling the stability constants of these ligands with $\mathrm{Ni}$ (II), it cannot be the only factor, else $\log K_{1}$ for BHEEN would be smaller, not larger, than that for $\mathrm{Cyp}_{2} \mathrm{EN}$.

We have also studied these three ligands using the X3LYP ${ }^{56}$ and PBEPBE $^{57,58}$ functionals with 6-31G(d,p), 6-31+G(d,p) and 6-311++G(d,p) basis sets in conjunction with QTAIM and NBO analyses. ${ }^{59}$ That work showed that the electron density, and its Laplacian, at the ring critical point of the cyclopentyl moiety in $\mathrm{Cyp}_{2} \mathrm{EN}$ is twice as large as that of the cyclohexyl moiety in $\mathrm{Cy}_{2} \mathrm{EN}$. We observed the formation of an intramolecular $\mathrm{NH}-\mathrm{O}$ hydrogen bond in all three ligands since values of the second-order stabilization energy $E^{(2)}$ caused by the charge transfer between the $\mathrm{O}$ lone-pair and the $\mathrm{N}-\mathrm{H}$ bond was non-zero. The strength of the $\mathrm{H}$-bond increased in the order $\mathrm{Cy}_{2} \mathrm{EN}>\mathrm{BHEEN}>\mathrm{Cyp}_{2} \mathrm{EN}$, consonant with a decrease in the $\mathrm{N}-\mathrm{H} \cdots \mathrm{O}$ distance in the three ligands. These two observations led to the tentative suggestions that (i) the increased electron density within the 5-member reinforcement rings contributes to the lower affinity of $\mathrm{Cyp}_{2} \mathrm{EN}$ for metal ions (in effect 
decreasing the basicity of the donor atoms) and (ii) that the ability of the ligand to transfer charge between orbitals, as described by $E^{(2)}$, is a factor that influences the ligand's ability to form complexes.

In further pursuance of the factors that control the stability constants of these three amino-alcohols (Figure 1) with Ni(II) we describe here DFT modeling and QTAIM analyses of the $\mathrm{Ni}$ (II) complexes of these ligands.

\section{Computational details}

Unless otherwise indicated, all calculations were performed using GAUSSIAN $03^{60}$ on a Linux workstation in a parallel environment; visualization of the molecular geometries were performed with the help of the GAUSSVIEW 03 suits of programs. ${ }^{61}$

The X3LYP functional is an admixture of an extended three-parameter (X3) exchange functional $^{56,62,63}$ coupled with the Lee-Yang-Parr (LYP) electron-correlation functional. ${ }^{64}$ Whilst a correlated functional such as B3LYP does not describe weak interactions very well because of an inadequate description of electron correlation, ${ }^{34,65,66}$ X3LYP does improve the description of softer interactions ${ }^{56,57,67,68}$ whilst describing the structure and electronic properties of molecular systems ${ }^{56,68-70}$ in a well-defined manner.

The structures of the complexes were energy-minimized in their electronic ground states; in order not to symmetry-bias the minimization, $\mathrm{C}_{1}$ symmetry was specified. $\mathrm{Ni}$ (II) was assumed to be high spin $(S=1)$. A tight criterion $\left(10^{-5}\right.$ hartree bohr $\left.{ }^{-1}\right)$ was specified for convergence.

The calculations of the normal mode frequencies were performed with the aid of analytical second derivatives of the UX3LYP potential energy surfaces in order to locate stationary points. A tight convergence criterion with ultra-fine integration grid was used. The resulting output from GAUSSIAN 03 with IMAG $=0$ ensured that the stationary points for all the structures belong to true minima and not to saddle points.

In addition to performing minimizations in vacuo we also performed minimizations in a simulated solvent environment, with self-consistent reaction field (SCRF) techniques. ${ }^{71-73}$ Dielectric continuum theories ${ }^{74-77}$ are widely used to describe hydration because accurate results are produced at a relatively low computational cost; we used the Conductor-like Polarizable Continuum Model (CPCM) ${ }^{78-82}$ in conjunction with the united atom (UA) cavitymodel in-tagged with Kohn-Sham $(\mathrm{KS})$ radii $(\mathrm{UAKS}){ }^{83,84}$ the radii were optimized with PBE0/6-31G $(\mathrm{d}, \mathrm{p})$ with solvent as water $(\varepsilon=78.39)$ for this purpose. For the calculations involving the simulation of solvent we set TSARE $=0.3$ and TSNUM $=100$ instead of the 
default settings in order to avoid the oscillatory behavior often encountered during optimization. Several starting geometries failed to converge and a number of trial structures were required before convergence was achieved. Despite many attempts, we were never able to produce a minimized structure of the trans complex of $\mathrm{Ni}(\mathrm{II})$ with $\mathrm{Cyp}_{2} \mathrm{EN}$ in a simulated solvated environment. However, as explained below, we believe this does not compromise the conclusions reached in this work.

The wavefunction files required for the analysis of the topological properties of the electron charge density using the atoms in molecules (AIM) framework of Bader ${ }^{50}$ were generated using the $\mathrm{X} 3 \mathrm{LYP} / 6-31+\mathrm{G}(\mathrm{d}, \mathrm{p})$ geometries by performing a single point calculation with a $6-311++G(d, p)$ basis set.

The topological properties of the electron density $(\rho(r))$, its Laplacian $\left(\nabla^{2} \rho(r)\right)$, the potential energy density $(V(r))$, the kinetic energy density $(G(r))$, and the total energy densities $(H(r))$ were evaluated at all the bond critical points (bcp's), ring critical points (rcp's), and cage critical points (ccp's) using the AIMALL ${ }^{85}$ and AIM2000 ${ }^{86,87}$ suite of programs.

The binding energy, $E_{\mathrm{b}}$, without zero-point vibrational correction, and the dissociation energy, $E_{\mathrm{d}}^{\mathrm{c}}$, incorporating the zero-point vibrational energy (ZPVE) correction, between the metal ion and the ligands of Figure 1 were calculated using eqs. 1 and 2, respectively, where the $E$ and $E_{\mathrm{zpvc}}$ terms are the gas-phase total uncorrected energies and zero-point corrected energies, respectively.

$$
\begin{aligned}
& E_{\mathrm{b}}\left(\left[\mathrm{Ni}(\text { ligand })\left(\mathrm{H}_{2} \mathrm{O}\right)_{2}\right]^{2+}\right)= \\
& E\left(\left[\mathrm{Ni}(\text { ligand })\left(\mathrm{H}_{2} \mathrm{O}\right)_{2}\right]^{2+}\right)-\left(E(\mathrm{Ni})^{2+}+\mathrm{E}(\text { ligand })+2 E\left(\mathrm{H}_{2} \mathrm{O}\right)\right) \\
& E_{\mathrm{d}}^{\mathrm{c}}\left(\left[\mathrm{Ni}(\text { ligand })\left(\mathrm{H}_{2} \mathrm{O}\right)_{2}\right]^{2+}\right)= \\
& \quad\left(E(\mathrm{Ni})^{2+}+\mathrm{E}_{z p v c}(\text { ligand })+2 E_{z p v c}\left(\mathrm{H}_{2} \mathrm{O}\right)\right)-E_{z p v c}\left(\left[\mathrm{Ni}(\text { ligand })\left(\mathrm{H}_{2} \mathrm{O}\right)_{2}\right]^{2+}\right)
\end{aligned}
$$

Both $E_{\mathrm{b}}$ and $E_{\mathrm{d}}{ }^{\mathrm{c}}$ were corrected for BSSE using the counterpoise procedure of Boys and Bernadii. ${ }^{88}$ 


\section{Results and Discussion \\ 3.1 Structure and Energetics}

We found that in the gas phase the cis complexes of $\mathrm{Ni}(\mathrm{II})$ with all three ligands are more stable than the trans complexes by between 2.6 and $8.0 \mathrm{kcal} \mathrm{mol}^{-1}$ (see Table S1 of the Supporting Information, where also the values of the uncorrected and ZPVE-corrected stabilization energies, BSSE energies, BSSE corrected energies, NPA charges on the metal $\left(\mathrm{Ni}^{Q}\right)$, and ligand-to-metal charge transfer $(\Delta Q)$ for the six complexes studied are listed; see also Table 1). Based upon $E_{\mathrm{d}}{ }^{\mathrm{c}}$ values, the predicted stability order of cis-[Ni(L)( $\left.\left(\mathrm{H}_{2} \mathrm{O}\right)_{2}\right]^{2+}$ complexes is $\mathrm{L}=\mathrm{Cy}_{2} \mathrm{EN}>\mathrm{L}=\mathrm{Cyp}_{2} \mathrm{EN}>\mathrm{L}=\mathrm{BHEEN}$, whereas the experimental $\log K_{1}$

values give $\mathrm{L}=\mathrm{Cy}_{2} \mathrm{EN}>\mathrm{L}=\mathrm{BHEEN}>>\mathrm{L}$ $=\mathrm{Cyp}_{2} \mathrm{EN}$.

The $\mathrm{Ni}-\mathrm{N}$ bond lengths are marginally longer in the cis complexes than in the trans complexes with differences between the two ranging from $0.003 \AA$ in the $\mathrm{Cy}_{2} \mathrm{EN}$ complex to $0.015 \AA$ in the BHEEN complex, Table 1. The $\mathrm{Ni}-\mathrm{OH}_{2}$ bond lengths are marginally longer in the cis complexes of BHEEN and $\mathrm{Cyp}_{2} \mathrm{EN}$ but shorter by over $0.03 \AA$ in the $\mathrm{Cy}_{2} \mathrm{EN}$ complex. The most significant variation occurs in the $\mathrm{Ni}-\mathrm{OH}$ bond lengths to the alcoholic donors of the ligands. In all cases, the cis complexes have shorter $\mathrm{Ni}-\mathrm{OH}$ bonds than the trans complexes; these differences range from (on average) a modest $0.027 \AA$ in the $\mathrm{Cy}_{2} \mathrm{EN}$ complex to a very significant $0.115 \AA$ in the $\mathrm{Cyp}_{2} \mathrm{EN}$ complex.

The difference in the stability of the $\mathrm{Ni}(\mathrm{II})$ complexes of three amino-alcohol ligands $\left(E_{\mathrm{d}}{ }^{\mathrm{c}}(\mathrm{BSSE})_{c i s}-E_{\mathrm{d}}{ }^{\mathrm{c}}(\mathrm{BSSE})_{\text {trans }}\right)$ correlates inversely with the difference of the
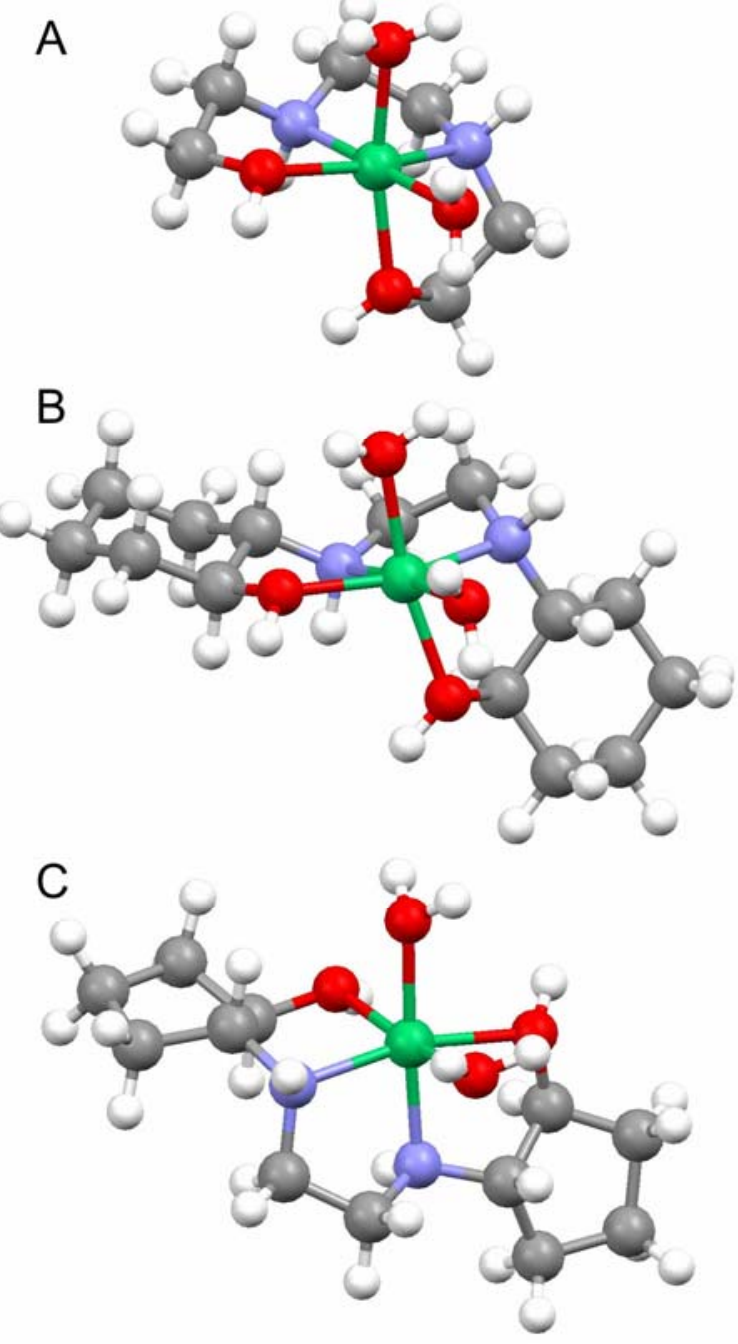

Figure 2. The energy-minimized structures (X3LYP/6-31+G(d,p), CPCM solvent model) of cis $\mathrm{Ni}(\mathrm{II})$ complexes, $\left[\mathrm{NiL}\left(\mathrm{H}_{2} \mathrm{O}\right)_{2}\right]^{2+}$ where $\mathrm{L}=$ (A) BHEEN, (B), $\mathrm{Cy}_{2} \mathrm{EN}$ and (C) $\mathrm{Cyp}_{2} \mathrm{EN}$. The average absolute value of the $\mathrm{N}-\mathrm{C}-\mathrm{C}-\mathrm{O}$ torsion, $\omega$, angle in the three complexes is (A) $52.5(2.1)^{\circ}$, (B) $51.9(2.9)^{\circ}$ and (C) $59.4(1.7)^{\circ}$. 
average metal-ligand bond length (to the four donor atoms of the amino-alcohol ligand and the two $\mathrm{H}_{2} \mathrm{O}$ ligands, Figure S1, Supporting Information), which correlation is largely (but not exclusively) determined by the $\mathrm{Ni}-\mathrm{OH}$ bond lengths to the alcoholic $\mathrm{O}$ donors.

Figure 2 shows the cis complexes of the three ligands energy-minimized in the presence of solvent; in all three complexes, one of the $(\mathrm{N}, \mathrm{O})$ chelate rings is in the $\delta$ conformation whilst the other is in the $\lambda$ conformation. In Table 2 are listed the average coordination bond lengths we found in our modeling of the cis structures, both in the gas phase and in solvent. We find that the $\mathrm{Ni}-\mathrm{OH}$ bonds increase monotonically in the order $\mathrm{Cy}_{2} \mathrm{EN}<\mathrm{BHEEN}<$ $\mathrm{Cyp}_{2} \mathrm{EN}$ whereas the $\mathrm{Ni}-\mathrm{N}$ bonds are similar in the $\mathrm{Cy}_{2} \mathrm{EN}$ and BHEEN complexes, and longer by about $0.017 \AA$ in the $\mathrm{Cyp}_{2} \mathrm{EN}$ complex. Conversely, the $\mathrm{Ni}-\mathrm{OH}_{2}$ bonds are longest in the $\mathrm{Cy}_{2} \mathrm{EN}$ complex, and shortest in the $\mathrm{Cyp}_{2} \mathrm{EN}$ complex, presumably in response to the decrease in steric crowding of the metal center as the $\mathrm{Ni}-\mathrm{L}$ bond lengths increase. There is a correlation (Figure 3 ) between $\log K_{1}$ values and the average $\mathrm{Ni}$-donor atom bond lengths, with the correlation dominated by the $\mathrm{Ni}-\mathrm{OH}$ bond lengths as these show the greatest variability.

We suspected that the longer $\mathrm{Ni}-\mathrm{OH}$ bonds in $\left[\mathrm{Ni}\left(\mathrm{Cyp}_{2} \mathrm{EN}\right)\left(\mathrm{H}_{2} \mathrm{O}\right)_{2}\right]^{2+}$ compared to the other two complexes are related to the rigidity imparted on the ligand by the cyclopentyl substituent on the pendent amino-alcohol arms. In order to assess this we examined the structures of $\mathrm{NH}_{2} \mathrm{CH}_{2} \mathrm{CH}_{2} \mathrm{OH}$ and $\mathrm{NH}_{2} \mathrm{CH}(\mathrm{R}) \mathrm{CH}(\mathrm{R}) \mathrm{OH}$, where $\mathrm{R}$ is either a cyclopentyl or cyclohexyl substituent on ethanolamine.

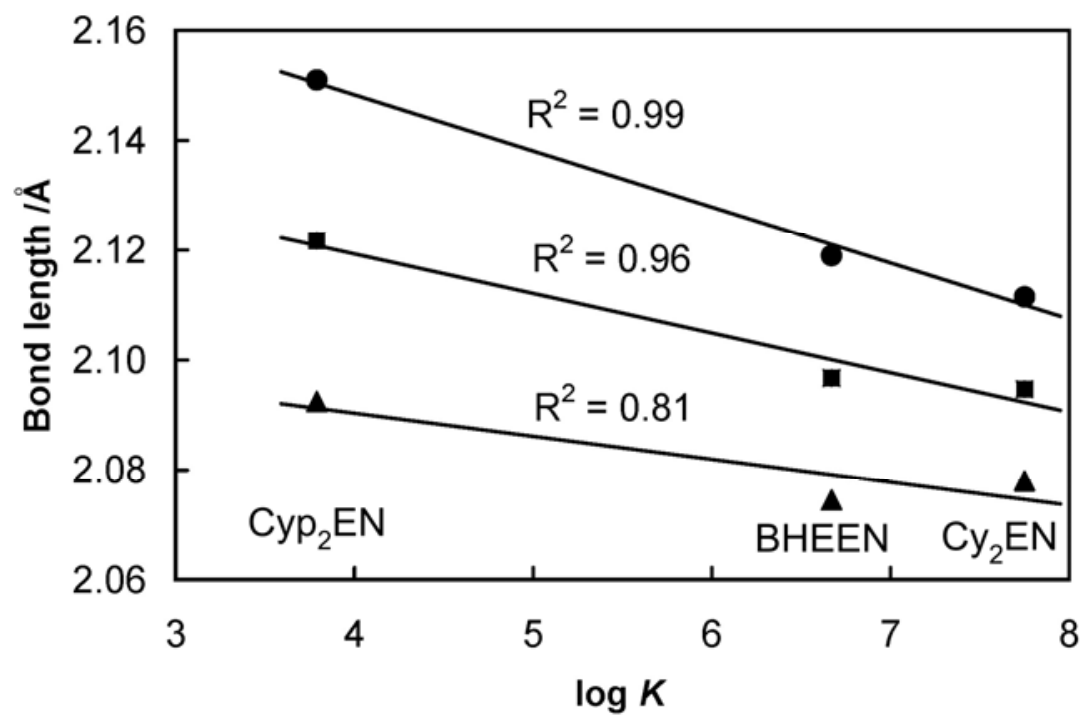

Figure 3. The correlation between the experimental $\log K_{1}$ values for cis$\left[\mathrm{NiL}\left(\mathrm{H}_{2} \mathrm{O}\right)_{2}\right]^{2+} \quad(\mathrm{L}=$ $\left.\mathrm{Cy}_{2} \mathrm{EN}, \mathrm{BHEEN}, \mathrm{Cyp}_{2} \mathrm{EN}\right)$ and the average bond lengths (X3LYP/6$31+\mathrm{G}(\mathrm{d}, \mathrm{p})$ in solvent) between the metal and all four donors of the aminoalcohol ligands $(\boldsymbol{\square})$, then, individually, the two $\mathrm{N}$ donors $(\boldsymbol{\Delta})$ and the two alcohol $\mathrm{O}$ donors $(\bullet)$.

We set the $\mathrm{N}-\mathrm{C}-\mathrm{C}-\mathrm{O}$ torsion, $\omega$, to be around $30^{\circ}$ so that the $\mathrm{N}$ and $\mathrm{O}$ atoms would be in the correct relative orientation to bind to a metal ion and then performed a geometry 
optimization $(\mathrm{X} 3 \mathrm{LYP} / 6-311+\mathrm{G}(\mathrm{d}, \mathrm{p}))$ of the three compounds. We also performed a frequency calculation on each energy-minimized structure not only to ensure that they corresponded to genuine minima, but also to determine the ZPVE-corrected values of the free energy, $G_{\text {calc }}$. We then constrained $\omega$ to the values observed in the energy-minimized Ni(II) structures (Figure 2) and performed a further energy-minimization.

The results are given in Table S2. (We have had to rely on the gas phase structures as we were unable, despite many attempts beginning from slightly different starting geometries, to obtain convergence for the cyclopentyl-containing amino-alcohol with constrained $\omega$.) The constraint caused an increase in $G_{\text {calc }}, \Delta G$, of $0.016 \mathrm{kcal} \mathrm{mol}^{-1}$ in $\mathrm{Cy}_{2} \mathrm{EN}, 0.066 \mathrm{kcal}$ $\mathrm{mol}^{-1}$ in BHEEN, and $2.017 \mathrm{kcal} \mathrm{mol}^{-1}$ in $\mathrm{Cyp}_{2} \mathrm{EN}$. The computed $\Delta G$ values correlate well with the observed trends in the $\mathrm{Ni}-\mathrm{OH}$ bond lengths as well as formation constants for the ML complexes, $\log K_{1}\left(\mathrm{Cy}_{2} \mathrm{EN}\right)>\log K_{1}(\mathrm{BHEEN})>>\log K_{1}\left(\mathrm{Cyp}_{2} \mathrm{EN}\right)$, strongly suggesting that the $\mathrm{Ni}-\mathrm{OH}$ bonds (involving alcoholic $\mathrm{O}$-atoms) contribute significantly to the overall stability of the complexes. The bonds between the $\mathrm{N}$ donors of the chelating ligands and $\mathrm{Ni}$ (II) are shorter and stronger than those between its $\mathrm{O}$ donors and the metal (vide infra); thus the latter are more susceptible to the topology of the chelating ligand, and in particular, the rigidity of the ligand introduced by the reinforcement in the NCCO pendent arms.

\subsection{Ligand Pre-Organization Energy and Complex Stability}

The stronger the complex between a metal and a ligand in aqueous solution, the more negative the value of the change in the Gibbs energy of the complexation reaction, $\Delta G_{\mathrm{r}}(\mathrm{aq})$, and hence the larger the formation constant. This well-known fact, however, does not provide insight into $w h y$, for instance, $\log K_{1}\left(\mathrm{Cy}_{2} \mathrm{EN}\right) \gg>\log K_{1}\left(\mathrm{Cyp}_{2} \mathrm{EN}\right)$. The overall energy change for a complexation reaction must be a competition between the stabilizing and the destabilizing energy contributions, the former resulting in a decrease in the overall energy, and the latter an increase. We therefore focused on the reorganization energy of the ligand by determining the difference in energy between the structure of the free ligand (available from our previous work ${ }^{52,89}$ ) and its structure when it has been reorganized into the conformation required for formation of the complex. We calculated the latter from a single point frequency calculation on the $\mathrm{Ni}(\mathrm{II})$ complexes from which had been deleted the metal ion and two $\mathrm{H}_{2} \mathrm{O}$ ligands. The values of $E(\mathrm{ZPVE})$ and $G$ of the free ligand and of the ligand in the conformation found in the metal complexes are listed in Table 3. 
The pre-organization energy is a penalty energy the ligand has to pay to form a complex; if a complex is formed spontaneously then the penalty energy is compensated for by the stabilizing energy contributions coming from, inter alia, the formation of coordination bonds. It is seen in Table 3 that $\mathrm{BHEEN}$ and $\mathrm{Cy}_{2} \mathrm{EN}$ require larger pre-organization energy $\Delta E$, by about 4 and $5 \mathrm{kcal} \mathrm{mol}^{-1}$, respectively, to form cis compared to trans complexes, although they are stronger in the gas phase (it is likely the same applies in the solvent; as we mentioned earlier, we were unable to optimize the trans complex involving the $\mathrm{Cyp}_{2} \mathrm{EN}$ ligand). Surprisingly, the trend in the pre-organization energy, as measured by $\Delta E$ and $\Delta G$, $\mathrm{Cyp}_{2} \mathrm{EN}<\mathrm{BHEEN}<\mathrm{Cy}_{2} \mathrm{EN}$, is exactly opposite to that observed for the formation constants. This clearly indicates that there must be stabilizing energy contributions which result in the observed experimental trend in the formation constants and which override the pre-organization energy. One of these factors, that the cis complexes have shorter $\mathrm{Ni}-\mathrm{OH}$ bonds than the trans complexes, was discussed above.

\subsection{Intramolecular Strain and Complex Stability}

Another factor that should be considered is the strain within the molecule once the complex has formed. The origin of intramolecular strain has been analyzed in detail by Wiberg; ${ }^{90}$ this involved evaluating the variation in bond lengths, bond angle distortions, torsional changes as well as non-bonded interactions. He concluded that usually bond angle distortion and non-bonded repulsions (commonly referred to as the steric effect) are the two most important components of the total strain. The difference between the bond path angle, BPA, defined as the limiting value of the angle subtended at a nucleus by two bond paths (vide infra), and the corresponding geometrical bond angle, GBA - the angle between the three nuclei in question - was used to quantify bond strain in the structures of many hydrocarbons. ${ }^{91-94}$ The properties of molecules have been related to the departure of the BPA from the GBA. ${ }^{91,92}$ The electronegativity of a carbon atom can be related to the BPAs and the geometrical strain. ${ }^{91}$ You et al..$^{95}$ expounded on this approach to evaluate the strain of a particular bent bond instead of the strain of the molecule as a whole.

Clearly, the more intramolecular strain is concentrated in a specific bond, the greater the bend in the bond path; one might therefore use the difference DIF $=|\mathrm{BPA}-\mathrm{GBA}|$ to quantify the concept of strain. This approach works well for covalently-linked atoms ${ }^{92-94}$ and was recently used by one of us to rationalize the difference is stability of $\mathrm{Zn}^{2+}$ complexes with nitrilotriacetic acid and nitrilotri-3-propanoic acid. ${ }^{96}$ 
The values of the BPAs and the GBAs, and their difference, for the Ni(II) complexes of the amino-alcohols under discussion, are listed in Tables S3 of the Supporting Information, whilst DIF values are summarized in Table 4. In this table, DIF(Tot) refers to the sum of the total DIF values, including contributions from the QTAIM-defined weak intramolecular interactions. Some of these are very large; for example, the $\mathrm{C} 18-\mathrm{H} 23 \cdots \mathrm{O} 3$ interaction in the cis-[Ni(BHEEN $\left.)\left(\mathrm{H}_{2} \mathrm{O}\right)_{2}\right]^{2+}$ complex has a GBA value of $110.5^{\circ}$ but a BPA of $0.9^{\circ}$ and so contributes $109.6^{\circ}$ to DIF(Tot). The complex involving Cyp $_{2} \mathrm{EN}$ appears to be most strained when measured by DIF(Tot). Indeed, the trans-[Ni(BHEEN $\left.)\left(\mathrm{H}_{2} \mathrm{O}\right)_{2}\right]^{2+}$ complex, which does not have intramolecular interactions, has by far the lowest DIF(Tot), yet is less stable than the cis complex by $2.595 \mathrm{kcal} \mathrm{mol}^{-1}$ (Table S1). We conclude that because of the very weakness of these interactions and their non-covalent nature, their inclusion in DIF values is probably not justified.

Omitting them gives the values $\operatorname{DIF}(1)$ in Table 4 . DIF(1) is much larger $\left(470^{\circ}\right)$ for $\left[\mathrm{Ni}\left(\mathrm{Cyp}_{2} \mathrm{EN}\right)\left(\mathrm{H}_{2} \mathrm{O}\right)_{2}\right]^{2+}$ than the other complexes, which is consistent with it having the smallest $\log K_{1}$ value. However, the value of $\operatorname{DIF}(1)$ for trans-[Ni(BHEEN)( $\left.\left.\mathrm{H}_{2} \mathrm{O}\right)_{2}\right]^{2+}$ complex is the smallest, inconsistent with the finding that the cis complex is more stable. Furthermore, for example, $\operatorname{DIF}(1)$ for cis-[Ni(Cy $\left.\left(\mathrm{Cy}_{2} \mathrm{EN}\right)\left(\mathrm{H}_{2} \mathrm{O}\right)_{2}\right]^{2+}>\operatorname{DIF}(1)$ for cis$\left[\mathrm{Ni}(\mathrm{BHEEN})\left(\mathrm{H}_{2} \mathrm{O}\right)_{2}\right]^{2+}\left(393^{\circ}\right.$ and $329^{\circ}$, respectively) yet $\mathrm{Cy}_{2} \mathrm{EN}$ forms the more stable complex. It appears that the DIF(1) values on their own are an insufficient index to account for the observed difference in complex stability.

Because the number of atoms (and hence bonds) is significantly different in these molecules, this may compromise the validity of $\operatorname{DIF}(1)$ as an index of complex stability. The coordination sphere is identical in all three complexes; hence the $\operatorname{DIF}(\mathrm{CR})$ values, which is a summation of the DIF values in the chelating rings around the metal ion, can be compared directly. Surprisingly we find that cis conformers are significantly more stressed around the central metal atom than the trans conformers.

An even larger relative difference is observed for the strain in the bite angles, DIF(BA). The values are smaller for the trans complexes than for the cis complexes even though the latter are the more stable (Table S1). Bite angles are often used to rationalize the relative stability of complexes; here, in the case of the more stable cis complexes, the DIF(BA) value is largest in the BHEEN complex and smallest in the $\mathrm{Cy}_{2} \mathrm{EN}$ complex, even though the latter has reinforced pendent arms. The same trend is observed when the strain in the chelating rings, $\mathrm{DIF}(\mathrm{CR})$, is considered. 
We conclude that DIF values are insufficient to account for the relative stability of these amino-alcohol complexes of $\mathrm{Ni}(\mathrm{II})$. Whilst intramolecular strain must be a factor, there clearly must be additional energy stabilizing contribution(s). We suggest that amongst these are the "non-bonded" intramolecular interactions.

\subsection{H-clashes and Intramolecular Weak Interactions}

The rationalization of the stability constants of the complexes between various metal ions and amino-alcohol ligands often relies on the usual geometrical parameters such as bond lengths and bite angles, and also on close $\mathrm{CH}^{\cdots} \mathrm{HC}$ contacts assessed from molecular structures usually obtained by X-ray diffraction methods. ${ }^{47,48}$ Even overlooking the fact that $\mathrm{H}$ atoms are very infrequently experimentally observable in X-ray diffraction experiments, we suggest that the structural analysis-based rationalization may not always be adequate and in fact could be misleading. For instance, it is known that the structural parameters do not have to correlate with the bond energy. ${ }^{26}$

The molecular graphs obtained from a QTAIM analysis of the cis structures energyminimized in solvent showed a number of $\mathrm{O} \cdots \mathrm{HC}$ and $\mathrm{CH} \cdots \mathrm{HC}$ weak intramolecular interactions, characterized by a bond path. We also examined all possible pairwise $\mathrm{CH} \cdots \mathrm{HC}$ interactions (excluding those between vicinal H's and $\mathrm{H}^{\prime} \mathrm{s}$ in a 1,4 relationship) in the structures to find cases in which $\mathrm{H}$ atoms approached to less than the sum of their van der Waals' radii (for this purpose we used a value of $1.20 \AA$ ) but which did not present with a bond path in the QTAIM analysis. We refer to these as $\mathrm{H}-\mathrm{H}$ or steric clashes.

Weak intramolecular interactions are present in all complexes except for trans$\left[\mathrm{Ni}(\mathrm{BHEEN})\left(\mathrm{H}_{2} \mathrm{O}\right)_{2}\right]^{2+}$ (see Table S4, Supporting Information). As an example, the structure obtained in the presence of solvent, and the relevant molecular graph, of cis$\left[\mathrm{Ni}(\mathrm{BHEEN})\left(\mathrm{H}_{2} \mathrm{O}\right)_{2}\right]^{2+}$ is shown in Figure 4; the others are illustrated in Figures $\mathrm{S} 2$ of the Supporting Information. There are two intramolecular bonding interactions $(\mathrm{O} 3-\mathrm{H} 23 \mathrm{C}$ and $\mathrm{O} 3-\mathrm{H} 15 \mathrm{C})$ with a bond path and one $\mathrm{H}-\mathrm{H}$ clash $(\mathrm{CH} 16 \cdots \mathrm{H} 26 \mathrm{C})$ in cis$\left[\mathrm{Ni}(\mathrm{BHEEN})\left(\mathrm{H}_{2} \mathrm{O}\right)_{2}\right]^{2+}$, whereas there are none in the trans conformer of this complex (Figure S2B, Supporting Information).

Because, as seen in Table S1, cis complexes are more stable than trans complexes, the data discussed above showed several surprises. First, a greater pre-organisation energy penalty is required for the ligands to fold into the conformation required to form the cis complex than the trans complex. Second, there is greater intramolecular strain in the cis complexes than in the trans complexes. Third, in the solvated complexes there is one $\mathrm{H}--\mathrm{H}$ 
clash in the cis conformer $(2.18 \AA)$ and none in the trans conformer of $\left[\mathrm{Ni}(\mathrm{BHEEN})\left(\mathrm{H}_{2} \mathrm{O}\right)_{2}\right]^{2+}$ and there are two in the cis conformer $(2.23$ and $2.30 \AA)$ and none in the trans $\left[\mathrm{Ni}\left(\mathrm{Cy}_{2} \mathrm{EN}\right)\left(\mathrm{H}_{2} \mathrm{O}\right)_{2}\right]^{2+}$. However, in compensation, the cis complexes have shorter average metal-ligand bond lengths than the trans complexes, and the greater the difference between the average bond lengths in the two, the greater the difference in their stability. This strongly suggests a causal inverse correlation between complex stability and average metalligand bond length. Indeed, as shown in Figure 3, there is a correlation between $\log K_{1}$ values and the average $\mathrm{Ni}$-ligand length, a correlation dominated by the $\mathrm{Ni}-\mathrm{OH}$ bond lengths as these show the greatest variability.

The values of $\rho_{\text {bcp }}$ of the $\mathrm{Ni}-\mathrm{OH}$ and $\mathrm{Ni}-\mathrm{OH}_{2}$ bonds are larger in the cis structures than in the trans structures, while the converse is true for the $\rho_{\text {bcp }}$ values of the $\mathrm{Ni}-\mathrm{N}$ bonds (Table S5, Supplementary Information). The difference $\rho_{\text {bcp }}($ cis-trans $)$ for the $\mathrm{Ni}-\mathrm{N}$ bonds is smaller for $\left[\mathrm{Ni}\left(\mathrm{Cy}_{2} \mathrm{EN}\right)\left(\mathrm{H}_{2} \mathrm{O}\right)_{2}\right]^{2+}$ than for the other two complexes, i.e., the $\mathrm{Ni}-\mathrm{N}$ bond strength favors the trans complex of $\left[\mathrm{Ni}\left(\mathrm{Cy}_{2} \mathrm{EN}\right)\left(\mathrm{H}_{2} \mathrm{O}\right)_{2}\right]^{2+}$ less than in the case of the other two ligands.

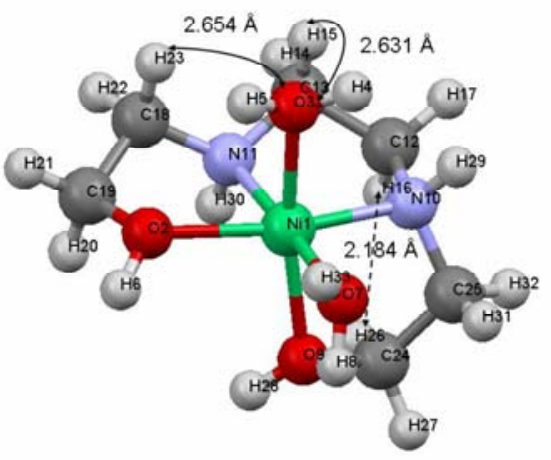

(a)

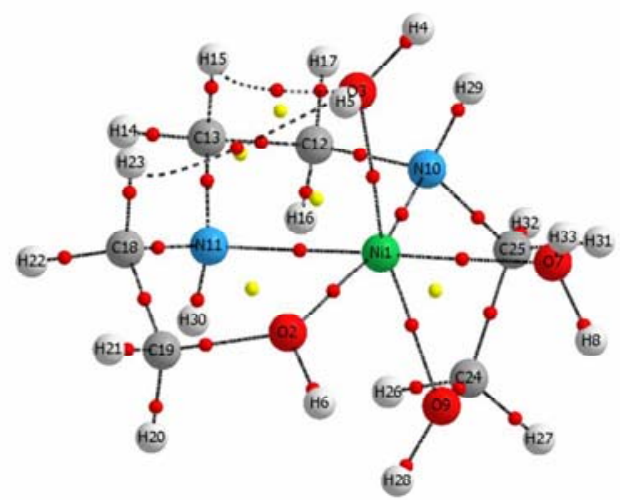

(b)

Figure 4. Solvent-optimized structure (a), where two intramolecular interactions and one close contact $\mathrm{CH} 16 \cdot \bullet \mathrm{H} 26 \mathrm{C}$ are shown as solid and dashed trace lines, respectively, and molecular graph (b) of the $c i s-\left[\mathrm{Ni}(\mathrm{BHEEN})\left(\mathrm{H}_{2} \mathrm{O}\right)_{2}\right]^{2+}$ complex.

The weak intramolecular $\mathrm{O} \cdots \mathrm{HC}$ and $\mathrm{CH}^{\cdots} \cdot \mathrm{HC}$ interactions may be an additional factor that makes the cis conformers more stable than the trans conformers as they are characterized by a bond path. Whilst the physical significance of the appearance of $\mathrm{CH}-\mathrm{HC}$ (or $\mathrm{H}-\mathrm{H}$ ) bonds in QTAIM analyses has prompted considerable debate (for example ${ }^{97-99}$ ), it has been reported that such a bond path represents a direct electron-exchange channel between atoms and therefore contributes to lowering their mutual interaction energy. ${ }^{100}$ Assuming that $E=$ $1 / 2 V(r)$ (as has been demonstrated for hydrogen bonds ${ }^{101}$ ) then we can estimate the differential 
stabilization between the cis and trans complexes ( $\delta E($ cis - trans) due to these weak intramolecular bonds (Table S6, Supporting Information). With the exception of $\left[\mathrm{Ni}\left(\mathrm{Cy}_{2} \mathrm{EN}\right)\left(\mathrm{H}_{2} \mathrm{O}\right)_{2}\right]^{2+}$ in solvent the cis complexes are preferred over the trans complexes, as the $\delta E($ cis - trans $)<0$. Even though $\delta E($ cis - trans $)=0.44 \mathrm{kcal} \mathrm{mol}^{-1}$ in the case of $\left[\mathrm{Ni}\left(\mathrm{Cy}_{2} \mathrm{EN}\right)\left(\mathrm{H}_{2} \mathrm{O}\right)_{2}\right]^{2+}$, the greater stability of the cis conformer (Table S1) clearly arises from other factors such as the more stable $\mathrm{Ni}-\mathrm{OH}$ bonds as mentioned above.

The above considerations lead to the conclusion that the overall stability of a complex is a result of the interplay between the stabilizing contributions (for example, the strength of the coordination bonds as measured by $\rho_{\text {bcp }}$ and intramolecular QTAIM-defined bonding interactions) and destabilizing contributions, such as strain energy due to bond angle distortion (as measured by the difference between BPA and GBA) and intramolecular close contacts without QTAIM-defined bond paths (intramolecular clashes which can be seen as non-bonded repulsion identified by Wiberg as one among major contributors to the total $\left.\operatorname{stain}^{90}\right)$. It is obvious that there are not net repulsive or attractive forces in a molecule at equilibrium, but the intramolecular H-clashes discussed here most likely must have resulted in locally increased strain energy and/or the repulsive Pauli interaction between occupied orbitals on the two fragments $(\mathrm{CH}-\mathrm{-HC})$ in the combined molecule.

As indicated at the beginning of this section, the conventional approach of rationalizing complex stability could be misleading. We will neglect the bite angles as they have almost the same value in all complexes. If one were to consider all the close contacts in the cis and trans conformers (three in the cis conformer and none in trans conformer of $\left[\mathrm{Ni}(\mathrm{BHEEN})\left(\mathrm{H}_{2} \mathrm{O}\right)_{2}\right]^{2+}$; four in the cis conformer and two in trans conformer of $\left.\left[\mathrm{Ni}\left(\mathrm{Cy}_{2} \mathrm{EN}\right)\left(\mathrm{H}_{2} \mathrm{O}\right)_{2}\right]^{2+}\right)$, or just the $\mathrm{CH}^{\cdots} \cdot \mathrm{HC}$ contacts (there is one in the cis conformer and none in the trans conformer of $\left[\mathrm{Ni}(\mathrm{BHEEN})\left(\mathrm{H}_{2} \mathrm{O}\right)_{2}\right]^{2+}$; there are two in the cis conformer and none in the trans conformer of $\left.\left[\mathrm{Ni}\left(\mathrm{Cy}_{2} \mathrm{EN}\right)\left(\mathrm{H}_{2} \mathrm{O}\right)_{2}\right]^{2+}\right)$ and using the conventional approach that views all such contacts as steric clashes, one would might predict (i) the cis conformers to be less stable than the trans conformers (but this is not supported by the $E_{\mathrm{d}}$ values) and (ii) $\left[\mathrm{Ni}\left(\mathrm{Cy}_{2} \mathrm{EN}\right)\left(\mathrm{H}_{2} \mathrm{O}\right)_{2}\right]^{2+}$ to be significantly weaker than $\left[\mathrm{Ni}(\mathrm{BHEEN})\left(\mathrm{H}_{2} \mathrm{O}\right)_{2}\right]^{2+}$ (and this is not supported by the experimental formation constants). Also, the number of $\mathrm{H}-$ clashes is largest in the $\mathrm{Cy}_{2} \mathrm{EN}$ complex (there are two), and one each in the complexes with $\mathrm{Cyp}_{2} \mathrm{EN}$ and BHEEN. On this basis one might expect $\log K_{1}\left(\mathrm{Cy}_{2} \mathrm{EN}\right)$ to be smaller than for the other two ligands, which is not the case. Clearly, an over-reliance on the presence or 
absence of $\mathrm{CH} \cdots \mathrm{HC}$ contacts, and particularly neglecting whether these may in fact be stabilizing bonding interactions as revealed by a QTAIM analysis, is unwise.

\subsection{Bond Character, Bond Strength and the Stability of Complexes}

Molecular graphs of complexes optimized in the gas phase are shown in Figure S3, Supporting Information. Table 5 lists the values of $\rho(r), \nabla^{2} \rho(r), V(r), G(r)$, and $H(r)$ at selected bcps, rcps and ccps of the solvent-optimized cis complexes. The values of these parameters for all conformers energy-optimized in the gas phase and solvent are shown in Table S4 and the atom numbering scheme used is given in Figure S2, Supporting Information.

The basicity of a neutral oxygen donor is increased by the inductive effect of alkyl substituents $^{15,102}$ so that the pendent hydroxyl groups of BHEEN (and related aminoalcohols) are potential electron donors for metal ions in aqueous solution. However, they must compete with $\mathrm{H}_{2} \mathrm{O}$ for the coordination sites of the metal and, for example, whilst potentially quadridentate, BHEEN is bidentate towards $\mathrm{Zn}(\mathrm{II})$ and tridentate towards $\mathrm{Cd}(\mathrm{II})$ with two and one alcohol moieties, respectively, uncoordinated by the metal ion, ${ }^{49}$ tridentate towards $\mathrm{Cu}(\mathrm{II}),{ }^{103,104}$ and bidentate towards $\mathrm{Pt}(\mathrm{II}){ }^{105,106}$ and $\mathrm{Pt}(\mathrm{IV}){ }^{105}$ The QTAIM results in solvent of the present complexes are in line with these observations: $\rho_{\text {bcp }}(\mathrm{Ni}-\mathrm{N})>>\rho_{\text {bcp }}(\mathrm{Ni}-$ $\mathrm{OH}) \approx \rho_{\text {bcp }}\left(\mathrm{Ni}-\mathrm{OH}_{2}\right)$, i.e., the amino donors form stronger bonds to the metal ion than the alcohol donors, and the alcohol donors have approximately the same bond strength towards the metal as $\mathrm{H}_{2} \mathrm{O}$ molecules and therefore may not always successfully compete with solvent for the metal ion.

There is usually a correlation between the strength of a chemical bond and the electron density at $\rho_{\text {bcp. }}{ }^{50}$ The Ni-N bonds are always slightly weaker in cis complexes in both phases, $\rho_{\text {bcp }}(\mathrm{Ni}-\mathrm{N})_{c i s}<\rho_{\text {bcp }}(\mathrm{Ni}-\mathrm{N})_{\text {trans }}$, whereas $\mathrm{Ni}-\mathrm{OH}$ bonds are always slightly stronger in cis complexes in both phases. This correlates very well with our comment above that the greater stability of the cis compared to the trans complexes appears to arise principally from the $\mathrm{Ni}-\mathrm{OH}$ bond lengths to the alcoholic donors of the ligands, which are shorter in the former than in the latter. Also, since (i) the strength of the $\mathrm{Ni}-\mathrm{OH}$ bonds increases significantly more then the strength of the $\mathrm{Ni}-\mathrm{N}$ bonds when going from the gas to the condensed phase, and (ii) on average the strength of all coordination bonds in cis complexes in solvent follows the trend $c i s-\mathrm{NiCy}_{2} \mathrm{EN}>c i s-\mathrm{NiBHEEN}>>$ cis-NiCyp ${ }_{2} \mathrm{EN}$, which resembles the trend in the formation constants, it is reasonable to assume that the cis 
complexes are also stronger in solvent. We note (Table S4) that whilst numerically different, the values of $\rho_{\text {bcp }}$ of the complexes energy minimized in the gas phase and in a solvent model follow the same trend. As we were unable to locate an energy-minimized structure of trans$\left[\mathrm{NiCyp}{ }_{2} \mathrm{EN}\left(\mathrm{H}_{2} \mathrm{O}\right)_{2}\right]^{2+}$, we shall concentrate on the gas phase structures for the moment.

Given the virtual invariance of the $\mathrm{Ni}-\mathrm{N}$ bond lengths, the stronger $\mathrm{Ni}-\mathrm{OH}$ bonding, in addition to the presence of more favorable intramolecular weak but bonding interactions (vide supra), the cis structures of these amino-alcohol ligands are more stable than the trans structures.

As we have shown in recent work on high-spin $\mathrm{Ni}(\mathrm{II})^{107}$, low-spin $\mathrm{Ni}$ (II) ${ }^{89}$ and highspin Co(II) ${ }^{108}$ complexes, QTAIM analysis is a useful tool in characterizing the nature of the bonding between a metal and its ligands. For a predominantly "shared" (covalent) interaction $\rho(r)>0.1$ au and $\nabla^{2} \rho(r)<0 .{ }^{109}$ In the case of a "closed shell" (ionic) interaction $\rho(r)$ is usually small $\left(\sim 10^{-2}\right.$ au for a H-bond and $\sim 10^{-3}$ au for a van der Waals' interaction $\left.{ }^{109}\right)$ whilst $\nabla^{2} \rho(r)>0$. At the boundary between the two regions, i.e., at $\nabla^{2} \rho(r) \sim 0$, the binding is an admixture of these two effects. The sign and magnitude of the total energy density ${ }^{108}$ at a bcp, $H(r)=G(r)+V(r)$, is also a useful indicator of the nature of the bonding. ${ }^{110,111}$ For a covalent interaction, the local electron potential energy density $V(r)$ dominates and $H(r)<0$, whereas for a predominantly ionic interaction, the local electron kinetic energy density $G(r)$ dominates and $H(r)>0 .{ }^{112-115}$ Another useful description is the ratio $|V(r)| / G(r) ;^{115,116}$ $|V(r)| / G(r)<1$ is characteristic of an ionic interaction, $|V(r)| / G(r)>2$ is diagnostic of a covalent interactions, and $1<|V(r)| / G(r)<2$ is indicative of interactions of intermediate character.

Focusing on the results for the cis complexes energy-minimized in the presence of solvent (Table 5) we note that the nature of the bonding is very similar in all three complexes and $\Delta Q$, the charge transferred from the ligands to the (formally) +2 ion, is nearly identical (Table S1, Supporting Information). It is not surprising to find nearly identical values of $\Delta Q$, as the extent of charge transfer can be anticipated to depend on (i) the electronegativity of the metal ion (Ni(II) in all three complexes in this case) and (ii) the polarizability ("softness") of the donor atoms $\left(2 \mathrm{~N}, 2 \mathrm{O}, 2 \mathrm{OH}_{2}\right.$ in all three cases here), and (iii) the structure of the backbone of the ligand interacting with a central metal ion (open chain ligands with two pendent alcoholic arms) is the same in all three cases. Whilst charge transfer from ligands to a metal ion must undoubtedly make an energetic contribution to complex stability, the very 
similar values of $\Delta Q$ for the three complexes under discussion indicate that the variation in $\log K_{1}$ values cannot be attributed to differential charge transfer to the central metal ion.

In the three complexes, see Table 5, among all metal-ligand bonds, the average value of $\rho(r)$ is small $(0.051 \mathrm{au}<\rho(r)<0.077 \mathrm{au})$ whilst $\nabla^{2} \rho(r)>0\left(0.27 \mathrm{au}<\nabla^{2} \rho(r)<0.33 \mathrm{au}\right)$; $H(r)$ is near zero, and $0.88<|V(r)| / G(r)<1.13$, near the boundary between a purely ionic and an ionic interaction with some covalent character. Specifically, using the ratio $|V(r)| / G(r)$ as a diagnostic, we note that the degree of covalency in the metal-ligand bonds decreases in the order $\mathrm{Ni}(\mathrm{II})-\mathrm{N}>\mathrm{Ni}(\mathrm{II})-\mathrm{OH}>\mathrm{Ni}(\mathrm{II})-\mathrm{OH}_{2}$, and that the latter can be classified as predominantly ionic (in cis- $\left[\mathrm{NiCy}_{2} \mathrm{EN}\left(\mathrm{H}_{2} \mathrm{O}\right)_{2}\right]^{2+}$, on average $|V(r)| / G(r)=0.881,0.997$ in the BHEEN complex, and 0.996 in the $\mathrm{Cyp}_{2} \mathrm{EN}$ complex). All the weak interactions identified by the QTAIM analysis and which lead to the formation of bond paths between remote atoms, are ionic in character $\left(\rho(r) \approx 0.008 \mathrm{au} ; \nabla^{2} \rho(r) \approx 0.03 \mathrm{au} ;|V(r)| / G(r) \approx 0.8\right)$.

Ferrugia et al. $^{117}$ have reported experimental and DFT (B3LYP/6-311G** on N, O; 6$31 \mathrm{G}^{* *}$ on $\mathrm{C}, \mathrm{H}$; Wachters $+\mathrm{f}$ on $\mathrm{Ni}$ ) charge density distribution in a $\mathrm{Ni}(\mathrm{II})$ amino-alcohol complex, $\left[\mathrm{Ni}\left(\mathrm{H}_{3} \mathrm{~L}\right)\right]\left[\mathrm{NO}_{3}\right]\left[\mathrm{PF}_{6}\right], \mathrm{H}_{3} \mathrm{~L}=N, N^{\prime}, N^{\prime \prime}$-tris(2-hydroxy-3-methylbutyl)-1,4,7-triazacyclononane. They found that the $\mathrm{Ni}-\mathrm{N}$ and $\mathrm{Ni}-\mathrm{O}$ bonds have intermediate character. For $\mathrm{Ni}-\mathrm{N} \rho(r)_{\exp }=0.0815, \rho(r)_{\mathrm{DFT}}=0.0788 ; \nabla^{2} \rho(r)_{\exp }=0.367 ; \nabla^{2} \rho(r)_{\mathrm{DFT}}=0.359$ and for Ni$\mathrm{OH} \rho(r)_{\exp }=0.0619, \rho(r)_{\mathrm{DFT}}=0.0573 ; \nabla^{2} \rho(r)_{\exp }=0.293 ; \nabla^{2} \rho(r)_{\mathrm{DFT}}=0.3333$. This is similar to the values we found for the present study, viz., $\rho(r)_{\mathrm{Ni}-\mathrm{OH}}<\rho(r)_{\mathrm{Ni}-\mathrm{N}}<0.1$ au; $\nabla^{2} \rho(r)$ $>0$.

In our previous examination of the structure of the free amino-alcohol ligand discussed in this work, we found ${ }^{59}$ that the electron density at the ring critical point, and its Laplacian, of the cyclopentyl moiety in $\mathrm{Cyp}_{2} \mathrm{EN}$ to be twice as large as those of the cyclohexyl moiety in $\mathrm{Cy}_{2} \mathrm{EN}$. As pointed out by a referee, this is unsurprising as the rcp in the cyclopentyl moiety is closer to the $\mathrm{C}$ atoms of the ring. However, we also noted ${ }^{59}$ that the second order stabilization energy $E^{(2)}$ obtained by an NBO analysis of the transfer of electron density from the alcoholic $\mathrm{O}$ atom of $\mathrm{Cy}_{2} \mathrm{EN}$ and $\mathrm{Cyp}_{2} \mathrm{EN}$ to a $\sigma^{*} \mathrm{NH}$ orbital to form an intramolecular $\mathrm{O}-$ $\mathrm{HN}$ hydrogen bond was larger in $\mathrm{Cy}_{2} \mathrm{EN}$ than in $\mathrm{Cyp}_{2} \mathrm{EN}$ and suggested that $\rho(\mathrm{r})$ at the rcp of the cycloalkyl rings might serve as an index of the Lewis basicity of the alcohol moiety. We now note (Table 3 ) that this difference in $\rho(r)$ at the rcp of the cyclohexyl and cyclopropyl moieties is preserved in their complexes with $\mathrm{Ni}(\mathrm{II})$, viz., $\rho_{\text {rcp }}=0.0185$ au for the cyclohexyl rings but 0.0397 au for the cyclopentyl rings, suggesting that $\rho_{\text {rcp }}$ may be a useful index of the ligand's basicity, which of course will influence the stability of its complexes with metal 
ions. It is also important to note (see Table S4, Supporting Information) that increased electron density within the cyclopentyl moiety results in a decrease of the electron density at the ring critical point of the 5-member chelating rings involving the alcoholic oxygen when compared with the analogous rep in the cis- $\mathrm{NiCy}_{2} \mathrm{EN}$ complex. As one of us suggested recently, ${ }^{118}$ a decrease in the electron density at a rcp of a structural chelating ring results in a weaker complex (smaller $\log K_{1}$ value) and this is also what we observe here.

\section{Conclusions}

The rationalization - let alone the prediction - of equilibrium constants for the formation of metal-ligand complexes is not simple. log $K_{1}$ values did not correlate simply with $E_{\mathrm{d}}{ }^{\mathrm{c}}$, and many factors will contribute to the observed values of $\log K_{1}$. Nevertheless, the work presented in this report, and our recent work on these amino-alcohol ligand systems, ${ }^{49,52,59,119,120}$ illustrates how computational chemistry methods can provide valuable insights into at least some of these factors. In addition, QTAIM analyses are invaluable in providing significant insight into the nature of metal-ligand bonding. We show in the present paper that the bond strength (as measured by $\rho(r)$ at bcp) in $\mathrm{Ni}(\mathrm{II})$ complexes of aqua-amino-alcohols complexes of the type $\left[\mathrm{Ni}(\mathrm{L})\left(\mathrm{H}_{2} \mathrm{O}\right)_{2}\right]^{2+}$, where $\mathrm{L}$ is a quadridentate $\mathrm{N}_{2} \mathrm{O}_{2}$ chelating ligand, decreases in the order $\mathrm{Ni}-\mathrm{N}>\mathrm{Ni}-\mathrm{OH} \geq \mathrm{Ni}-\mathrm{OH}_{2}$, and that, whilst the bonds are predominantly ionic, they have some covalent character which decreases in the order $\mathrm{Ni}-\mathrm{N}>\mathrm{Ni}-\mathrm{OH}>\mathrm{Ni}-\mathrm{OH}_{2}$, with $\mathrm{Ni}-\mathrm{OH}_{2}$ bonds close to being purely ionic. It is known that the structure of amino-alcohols in the solid state is controlled by weak interactions; ${ }^{119,120}$ we show here that intramolecular interactions will also play a role in determining what conformation a metal-ligand complex will adopt. We predict that complexes of the form $\left[\mathrm{Ni}(\mathrm{L})\left(\mathrm{H}_{2} \mathrm{O}\right)_{2}\right]^{2+}$ will prefer the cis over the trans conformation because of (i) stronger bonding to alcohol donors and (ii) more favorable intramolecular interactions. Among the factors that will determine the magnitude of $\log K_{1}$, we have previously shown that the pre-organization of the ligand for coordination to the metal is likely to be an important factor. ${ }^{52}$ We show in the present work that the flexibility of the ligand, and in particular its ability to accommodate the topology of the interaction of the metal, will play an important role. This (and its poor pre-organization ${ }^{52}$ ) is the most likely reason why $\mathrm{Cyp}_{2} \mathrm{EN}$ is a considerably poorer ligand for $\mathrm{Ni}(\mathrm{II})$ than $\mathrm{Cy}_{2} \mathrm{EN}$. Finally, the ability of the ligand to donate electron density to the metal is likely to be important. We show in the present work, confirming an earlier calculation on the free ligands, ${ }^{59}$ that the 
electron density at the rcp of the cyclopentyl moieties in $\mathrm{Cyp}_{2} \mathrm{EN}$ is higher than that in the cyclohexyl moieties of $\mathrm{Cy}_{2} \mathrm{EN}$. We interpret this to mean that $\mathrm{Cyp}_{2} \mathrm{EN}$ is a poorer donor of electron density to a Lewis acid than $\mathrm{Cy}_{2} \mathrm{EN}$; indeed, there is a good correlation (Figure S5) between the sum of the two acid dissociation constants of the amino groups of BHEEN, ${ }^{54}$ $\mathrm{Cyp}_{2} \mathrm{EN}$ and $\mathrm{Cy}_{2} \mathrm{EN}^{55}$ - a proxy measure of the donor ability of a ligand towards a Lewis acid - and $\log K_{1}$. We also conclude that the conventional explanation of complex stability in these sorts of complexes (based on considerations of bond lengths, bite angles and H-clashes) could be inadequate and indeed might be misleading.

Acknowledgments I.C. acknowledges financial support from National Research Foundation, Pretoria, and the University of Pretoria. H.M.M. acknowledges funding by the South African Research Chairs Initiative of the Department of Science and Technology administered by the National Research Foundation, Pretoria, the Mellon Foundation through grants administered by the University of the Witwatersrand, and the University Research Committee of the University of the Witwatersrand.

Supporting Information Available. A tabulation of the basis set superposition errors, the uncorrected binding energies, the ZPVE-corrected dissociation energies, and the difference between these values for the cis and trans isomers, the partial charge on the $\mathrm{N} \mathrm{i}$ ion in its complexes with the amino-alcohol ligands obtained from a X3LYP/6-31+G(d,p) study in the gas phase; strain analysis in the complexes of $\mathrm{Ni}(\mathrm{II})$ with BHEEN, $\mathrm{Cy}_{2} \mathrm{EN}$ and $\mathrm{Cyp}_{2} \mathrm{EN}$ involving bond path angles (BPA) and geometric bond angles (GBA); topological properties of $\mathrm{Ni}$ (II) complexes with amino-alcohol ligands in the gas phase and solvent; a comparison of the electron density at the bond critical points of the metal-ligand bonds in the gas phase structures of cis and trans complexes of Ni(II) and the aminoalcohol ligands; and a tabulation of the differential stabilization from weak energy-lowering interactions in the cis and trans complexes. Figures show how the difference in the stability of the $\mathrm{Ni}(\mathrm{II})$ complexes of the three amino alcohol ligands correlates inversely with the difference of the average metal-ligand bond lengths; from data in the Cambridge Structural Database, the dependence of the metal- $\mathrm{N}$ bond length and the metal- $\mathrm{O}$ bond length on the $\mathrm{N}-\mathrm{C}-\mathrm{C}-\mathrm{O}$ torsion, $\omega$, in chelate complexes of the late metals of the first transition series $(\mathrm{Co}, \mathrm{Ni}, \mathrm{Cu}, \mathrm{Zn})$; molecular graphs of the cis and the trans complexes of $\mathrm{Ni}(\mathrm{II})$ with the three amino-acid ligands; the atom numbering scheme used in the QTAIM analysis; and the correlation between $\log K_{1}$, the formation constant of the $\mathrm{Ni}$ (II) complex with the amino-alcohol ligands $\mathrm{Cyp}_{2} \mathrm{EN}, \mathrm{BHEEN}$ and $\mathrm{Cy}_{2} \mathrm{EN}$, and the sum of the two acid dissociation constants of the two amino groups of the ligand, a measure of the donor power of the ligand towards a Lewis acid. $37 \mathrm{pp}$. This information is available free of charge via the Internet at http://pubs.acs.org. 
Table 1. A Comparison of the Bond Length $(\AA)$ in Cis and Trans Ni(II) Amino-Alcohol Complexes (from a X3LYP/6-31+G(d,p) Study in the Gas Phase)

\begin{tabular}{|c|c|c|c|c|c|c|}
\hline \multirow[t]{2}{*}{ Complex } & \multicolumn{3}{|c|}{$\Delta$ Bond lengths (cis - trans) } & \multirow{2}{*}{$\begin{array}{c}\Delta(\mathrm{Av} \text { Ni-Lig }) \\
\text { bond }\end{array}$} & \multirow{2}{*}{$\begin{array}{c}\Delta(\mathrm{Av} \mathrm{Ni}-\mathrm{X}) \\
\text { bond }(\mathrm{X}=\mathrm{O}, \mathrm{N})\end{array}$} & \multirow{2}{*}{$\begin{array}{c}\Delta E_{\mathrm{d}}^{\mathrm{c}}(\mathrm{BSSE}) \\
/ \mathrm{kcal} \mathrm{mol}^{-1} \\
(\text { cis }- \text { trans })\end{array}$} \\
\hline & $\mathbf{N i}-\mathbf{N}$ & $\mathrm{Ni}-\mathrm{OH}$ & $\mathrm{Ni}-\mathrm{OH}_{2}$ & & & \\
\hline$\left[\mathrm{Ni}(\mathrm{BHEEN})\left(\mathrm{H}_{2} \mathrm{O}\right)_{2}\right]^{2+}$ & 0.015 & -0.056 & 0.003 & -0.021 & -0.013 & 2.595 \\
\hline$\left[\mathrm{Ni}\left(\mathrm{Cy}_{2} \mathrm{EN}\right)\left(\mathrm{H}_{2} \mathrm{O}\right)_{2}\right]^{2+}$ & 0.003 & -0.027 & -0.032 & -0.012 & -0.019 & 3.514 \\
\hline$\left[\mathrm{Ni}\left(\mathrm{Cyp}_{2} \mathrm{EN}\right)\left(\mathrm{H}_{2} \mathrm{O}\right)_{2}\right]^{2+}$ & 0.009 & -0.115 & 0.010 & -0.053 & -0.032 & 8.028 \\
\hline
\end{tabular}

Table 2. The Average Bond Lengths (X3LYP/6-31+G(d,p)) in cis- $\left[\mathrm{NiL}\left(\mathrm{H}_{2} \mathrm{O}\right)_{2}\right]^{2+}$ Complexes $\left(\mathrm{L}=\mathrm{Cy}_{2} \mathrm{EN}, \mathrm{BHEEN}\right.$, and $\left.\mathrm{Cyp}_{2} \mathrm{EN}\right)$.

\begin{tabular}{lccccccccc}
\hline Ligand & & \multicolumn{2}{c}{ All Ni-donor bonds $/ \AA$} & \multicolumn{2}{c}{ Ni-OH bonds $/ \AA$} & \multicolumn{2}{c}{ Ni-N bonds $/ \AA$} & \multicolumn{2}{c}{ Ni-OH $/ \AA$} \\
& $\log \boldsymbol{K}_{\mathbf{1}}$ & solution & gas & solution & gas & solution & gas & solution & gas \\
\hline $\mathrm{Cy}_{2} \mathrm{EN}$ & 7.75 & 2.102 & 2.116 & 2.112 & 2.120 & 2.078 & 2.078 & 2.115 & 2.150 \\
$\mathrm{BHEEN}$ & 6.67 & 2.102 & 2.118 & 2.119 & 2.133 & 2.075 & 2.083 & 2.114 & 2.139 \\
$\mathrm{Cyp}_{2} \mathrm{EN}$ & 3.79 & 2.117 & 2.133 & 2.151 & 2.162 & 2.093 & 2.097 & 2.109 & 2.139 \\
\hline
\end{tabular}


Table 3. Ligand (L) Pre-Organization Energies, $\Delta E$ and $\Delta G$, Obtained From Energy Differences for [L(in complex) $-\mathrm{L}($ free $)]$.

\begin{tabular}{|c|c|c|c|c|c|c|c|}
\hline \multirow[t]{2}{*}{ Ligand } & \multirow[t]{2}{*}{ Complex } & \multicolumn{2}{|c|}{ Free ligand $/ \mathbf{a u}^{\mathrm{a}}$} & \multicolumn{2}{|c|}{ Ligand in complex /au ${ }^{a, b}$} & \multicolumn{2}{|c|}{$\begin{array}{c}\text { Pre-organization } \\
\text { energy } / \mathrm{kcal} \mathrm{mol}^{-1}\end{array}$} \\
\hline & & $E(\mathrm{ZPVE})_{\mathrm{f}}$ & $\overline{G_{\mathrm{f}}}$ & $E(\mathrm{ZPVE})_{\mathrm{c}}$ & $\overline{G_{\mathrm{c}}}$ & $\Delta E$ & $\Delta G$ \\
\hline \multirow[t]{2}{*}{ BHEEN } & cis & -497.81099 & -497.85192 & -497.77085 & -497.80960 & 25.2 & 26.6 \\
\hline & trans & & & -497.77750 & -497.81432 & 21.0 & 23.6 \\
\hline \multirow[t]{2}{*}{$\mathrm{Cy}_{2} \mathrm{EN}$} & cis & -809.59611 & -809.64471 & -809.55200 & -809.59759 & 27.7 & 29.6 \\
\hline & trans & & & -809.55972 & -809.60757 & 22.8 & 23.3 \\
\hline $\mathrm{Cyp}_{2} \mathrm{EN}$ & cis & -731.04655 & -731.09538 & -731.00876 & -731.05530 & 23.7 & 25.2 \\
\hline
\end{tabular}

${ }^{a}$ Computed at the X3LYP/6-31+G(d,p) level of theory in solvent; ${ }^{b}$ energies obtained from a single point frequency calculations involving the ligand in the conformation in which it is found in the $\mathrm{Ni}$ (II) complex.

Table 4. Intramolecular Strain Energy Analysis from the Absolute Difference Between Bond Path Angle and Geometrical Bond Angle

\begin{tabular}{|c|c|c|c|c|}
\hline \multirow[b]{2}{*}{ Complex } & \multicolumn{4}{|c|}{ DIF $=\mid$ BPA-GBA $\mid / \operatorname{deg}$} \\
\hline & $\begin{array}{c}\text { Total } \\
\text { DIF(Tot) }\end{array}$ & $\begin{array}{c}\text { Intramolecular } \\
\text { bonds excluded } \\
\text { DIF(1) } \\
\end{array}$ & $\begin{array}{c}\text { Coordination } \\
\text { rings only } \\
\text { DIF(CR) }{ }^{a} \\
\end{array}$ & $\begin{array}{c}\begin{array}{c}\text { Bite angles } \\
\text { only } \\
\text { DIF(BA) }\end{array} \\
\end{array}$ \\
\hline$c i s-\left[\mathrm{Ni}(\mathrm{BHEEN})\left(\mathrm{H}_{2} \mathrm{O}\right)_{2}\right]^{2+}$ & 582 & 329 & 61 & 32 \\
\hline trans $-\left[\mathrm{Ni}(\mathrm{BHEEN})\left(\mathrm{H}_{2} \mathrm{O}\right)_{2}\right]^{2+}$ & 324 & 228 & 48 & 18 \\
\hline$c i s-\left[\mathrm{Ni}\left(\mathrm{Cy}_{2} \mathrm{EN}\right)\left(\mathrm{H}_{2} \mathrm{O}\right)_{2}\right]^{2+}$ & 644 & 393 & 57 & 26 \\
\hline trans $-\left[\mathrm{Ni}\left(\mathrm{Cy}_{2} \mathrm{EN}\right)\left(\mathrm{H}_{2} \mathrm{O}\right)_{2}\right]^{2+}$ & 604 & 392 & 38 & 10 \\
\hline cis-[Ni(Cyp $\left.\left.{ }_{2} \mathrm{EN}\right)\left(\mathrm{H}_{2} \mathrm{O}\right)_{2}\right]^{2+}$ & 808 & 470 & 58 & 28 \\
\hline
\end{tabular}

${ }^{\mathrm{a}} \mathrm{CR}=$ coordination ring, ${ }^{\mathrm{b}} \mathrm{BA}=$ bite angle 
Table 5. Selected QTAIM Properties of the Bond and Ring Critical Points of Cis Complexes of Ni(II) and Amino-Alcohol Ligands as Determined at the X3LYP/6-311++G(d,p) Level of Theory of the X3LYP/6-31+G(d,p) Energy-Minimized Structures Using a CPCM Solvent Model. ${ }^{\mathrm{a}}$

\begin{tabular}{|c|c|c|c|c|c|c|c|c|}
\hline & & & $\rho$ & $\nabla^{2} \rho$ & $\boldsymbol{V}$ & $\boldsymbol{G}$ & $\boldsymbol{H}$ & $|\boldsymbol{V}| / \boldsymbol{G}$ \\
\hline \multicolumn{9}{|c|}{$c i s-\left[\mathrm{Ni}(\mathrm{BHEEN})\left(\mathrm{H}_{2} \mathrm{O}\right)_{2}\right]^{2+}$} \\
\hline \multirow[t]{10}{*}{ Coordination sphere } & Ligand & & & & & & & \\
\hline & BHEEN & $\mathrm{Ni}-\mathrm{N}$ & 0.07731 & 0.32651 & -0.10567 & 0.09365 & -0.01202 & 1.12838 \\
\hline & & $\mathrm{Ni}-\mathrm{OH}$ & 0.05463 & 0.30166 & -0.07688 & 0.07615 & -0.00073 & 1.00963 \\
\hline & & $\mathrm{Ni}-\mathrm{OH}_{2}$ & 0.05374 & 0.31140 & -0.07734 & 0.07760 & 0.00026 & 0.99671 \\
\hline & & $\mathrm{Ni}-\left(\mathrm{OH}, \mathrm{OH}_{2}\right)$ & 0.05419 & 0.30653 & -0.07711 & 0.07687 & -0.00024 & 1.00311 \\
\hline & & $\mathrm{Ni}-\mathrm{X}^{\mathrm{b}}$ & 0.06189 & 0.31319 & -0.08663 & 0.08247 & -0.00417 & 1.05053 \\
\hline & & $\mathbf{R C P}$ & & & & & & \\
\hline & & $(\mathrm{N}, \mathrm{N})$ chelate & 0.02286 & 0.11533 & -0.02105 & 0.02494 & 0.00389 & \\
\hline & & $(\mathrm{N}, \mathrm{O})$ chelate & 0.02075 & 0.10720 & -0.01956 & 0.02318 & 0.00362 & \\
\hline & & Average all RCPs & 0.02145 & 0.10991 & -0.02005 & 0.02377 & 0.00371 & \\
\hline \multirow[t]{6}{*}{ Weak interactions } & & ВCP & & & & & & \\
\hline & $\mathrm{O} \cdots \mathrm{H}-\mathrm{C}(2.654 \AA)$ & $\mathrm{O} 3 \cdots \mathrm{H} 23 \mathrm{C} 18$ & 0.00752 & 0.03008 & -0.00524 & 0.00638 & 0.00114 & 0.82142 \\
\hline & $\mathrm{O} \cdots \mathrm{H}-\mathrm{C}(2.631 \AA)$ & $\mathrm{O} 3 \cdots \mathrm{H} 15 \mathrm{C} 13$ & 0.00821 & 0.03078 & -0.00552 & 0.00661 & 0.00109 & 0.83536 \\
\hline & & $\mathrm{RCP}$ & & & & & & \\
\hline & & Ni1 O3 H23 C18 N11 & 0.00809 & 0.03415 & -0.00588 & 0.00721 & 0.00133 & \\
\hline & & Ni1 O3 H15 C13 N11 & 0.00752 & 0.03137 & -0.00540 & 0.00662 & 0.00122 & \\
\hline
\end{tabular}

\section{$c i s-\left[\mathrm{Ni}\left(\mathrm{Cy}_{2} \mathrm{EN}\right)\left(\mathrm{H}_{2} \mathrm{O}\right)_{2}\right]^{2+}$}

Coordination Sphere Ligand

$\begin{array}{ll}\mathrm{Cy}_{2} \mathrm{EN} & \mathbf{B C P} \\ & \mathrm{Ni}-\mathrm{N} \\ \mathrm{Ni}-\mathrm{OH} \\ \mathrm{Ni}-\mathrm{OH}_{2} \\ \mathrm{Ni}-\left(\mathrm{OH}, \mathrm{OH}_{2}\right) \\ \mathrm{Ni}-\mathrm{X}^{\mathrm{b}} \\ \mathbf{R C P}\end{array}$

$\begin{array}{llrrrr}0.07674 & 0.32234 & -0.10443 & 0.09251 & -0.01192 & 1.12888 \\ 0.05558 & 0.31331 & -0.07945 & 0.07889 & -0.00056 & 1.00709 \\ 0.05387 & 0.30568 & -0.07673 & 0.08706 & 0.01033 & 0.88130 \\ 0.05473 & 0.30950 & -0.07809 & 0.08297 & 0.00489 & 0.94110 \\ 0.06206 & 0.31378 & -0.08687 & 0.08615 & -0.00072 & 1.00831\end{array}$




\begin{tabular}{|c|c|c|c|c|c|c|c|c|}
\hline & & & $\rho$ & $\nabla^{2} \rho$ & $\boldsymbol{V}$ & $G$ & $\boldsymbol{H}$ & $|\boldsymbol{V}| / \boldsymbol{G}$ \\
\hline \multirow{13}{*}{ Weak interactions } & & $(\mathrm{N}, \mathrm{N})$ chelate & 0.02196 & 0.10954 & -0.02007 & 0.02373 & 0.00366 & \multirow{13}{*}{$\begin{array}{l}0.84739 \\
0.80754\end{array}$} \\
\hline & & $(\mathrm{N}, \mathrm{O})$ chelate & 0.02071 & 0.10538 & -0.01943 & 0.02289 & 0.00346 & \\
\hline & & Average all RCPs & 0.02113 & 0.10677 & -0.01964 & 0.02317 & 0.00352 & \\
\hline & & Cyclohexyl moieties & 0.01851 & 0.11116 & -0.01664 & 0.02222 & 0.00557 & \\
\hline & & $\mathbf{B C P}$ & & & & & & \\
\hline & $\mathrm{O} \cdots \mathrm{HC}(2.587 \AA)$ & $\mathrm{O} 3 \cdots \mathrm{H} 40 \mathrm{C} 10$ & 0.00850 & 0.03026 & -0.00556 & 0.00656 & 0.00100 & \\
\hline & $\mathrm{CH} \cdots \mathrm{HC}(2.303 \AA)$ & $\mathrm{H} 41 \cdots \mathrm{H} 30$ & 0.00761 & 0.02468 & -0.00418 & 0.00517 & 0.00100 & \\
\hline & & $\mathbf{R C P}$ & & & & & & \\
\hline & & Ni1 O3 H40 C10 N7 & 0.00798 & 0.03363 & -0.00574 & 0.00707 & 0.00134 & \\
\hline & & Ni1 O4 C12 H30 H41 C9 N7 & 0.00647 & 0.02679 & -0.00435 & 0.00552 & 0.00118 & \\
\hline & & N6 C8 C9 H41 H30 C12 C13 & 0.00596 & 0.02790 & -0.00421 & 0.00559 & 0.00138 & \\
\hline & & $\mathbf{C C P}$ & & & & & & \\
\hline & & $\begin{array}{l}\text { Ni1 O4 N6 N7 C8 C9 C12 C13 C14 } \\
\text { C15 C16 H30 H41 }\end{array}$ & 0.00583 & 0.02794 & -0.00443 & 0.00571 & 0.00128 & \\
\hline
\end{tabular}

$c i s-\left[\mathrm{Ni}\left(\mathrm{Cyp}_{2} \mathrm{EN}\right)\left(\mathrm{H}_{2} \mathrm{O}\right)_{2}\right]^{2+}$

Coordination Sphere Ligand

$\mathrm{Cyp}_{2} \mathrm{EN}$

BCP

$\mathrm{Ni}-\mathrm{N}$

$\mathrm{Ni}-\mathrm{OH}$

$\mathrm{Ni}-\mathrm{OH}_{2}$

$\mathrm{Ni}-\left(\mathrm{OH}, \mathrm{OH}_{2}\right)$

$\mathrm{Ni}-\mathrm{X}^{\mathrm{b}}$

RCP

$(\mathrm{N}, \mathrm{N})$ chelate

$(\mathrm{N}, \mathrm{O})$ chelate

Average all RCPs

Cyclopentyl moieties

$\begin{array}{llllr}0.07470 & 0.30788 & -0.09986 & 0.08841 & -0.01144 \\ 0.05143 & 0.27034 & -0.07015 & 0.06887 & -0.00128 \\ 0.05407 & 0.31581 & -0.07830 & 0.07862 & 0.00033 \\ 0.05275 & 0.29307 & -0.07422 & 0.07375 & -0.00048 \\ 0.06007 & 0.29801 & -0.08277 & 0.07864 & -0.00413 \\ & & & & \\ 0.02258 & 0.11271 & -0.02061 & 0.02439 & 0.00378 \\ 0.01988 & 0.09810 & -0.01888 & 0.02170 & 0.00282 \\ 0.02078 & 0.10297 & -0.01946 & 0.02260 & 0.00314 \\ 0.03971 & 0.22502 & -0.04579 & 0.05102 & 0.00524\end{array}$

Weak interactions

\section{BCP}
$\mathrm{O} \cdots \mathrm{HC}(2.587 \AA)$
$\mathrm{O} 3 \cdots \mathrm{H} 21 \mathrm{C} 18$
O $\cdots$ HC $(2.623 \AA)$
$\mathrm{O} 3 \cdots \mathrm{H} 15 \mathrm{C} 13$

0.00852
0.00822

$\begin{array}{ll}0.03146 & -0.00573 \\ 0.03069 & -0.00550\end{array}$

$0.00680 \quad 0.00106$

0.84339 


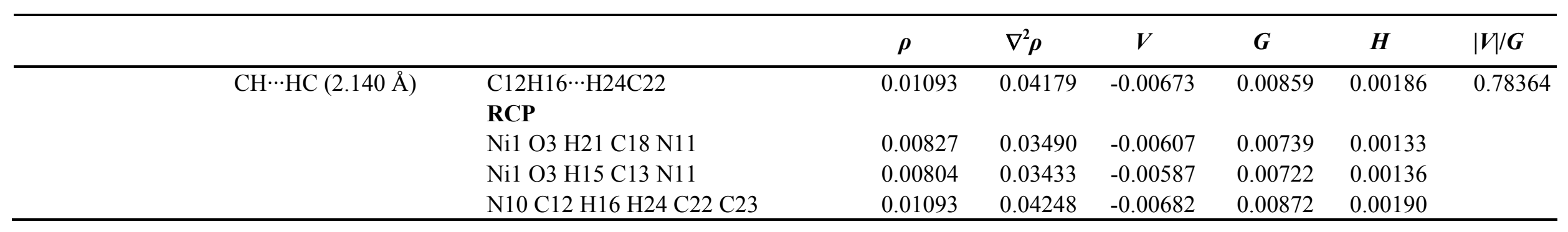

${ }^{a}$ All values in au. Atom numbering is given in Figure S3. Only average values are given; for full table see Table S4 of the Supplementary Information. ${ }^{\mathrm{b}} \mathrm{X}$ refers to all 6 donor atoms. 


\section{References}

(1) Hancock, R. D.; Martell, A. E. Metal Complexes in Aqueous Solutions; Plenum Press: New York, 1996.

(2) Frausto da Silva, J. J. R.; Williams, R. J. P. The Biological Chemistry of the Elements: the Inorganic Chemistry of Life; Clarendon Press: Oxford, 1991.

(3) Lippard, S. J.; Berg, J. M. Principles of Bioinorganic Chemistry; University Science Books: Mill Valley, CA, 1994.

(4) Albert, A. Selective Toxicity: the Physico-chemical Basis of Therapy, 7th ed.; Chapman and Hall: London, 1985.

(5) Andersen, O.; Aaseth, J. Environ. Health Perspec. 2002, 110, 887-890.

(6) Adrian, D. C. Trace Metals in the Terrestrial Environment; SpringerVerlag: Berlin, 1986.

(7) Toxic Metals in Soil-Plant Systems; Ross, S. M., Ed.; Wiley: Chichester, 1994.

(8) Han, K. N. Metallurg. Mat. Trans. B 2003, 34B, 757-767.

(9) Fuks, L.; Majdan, M. Min. Process. Extract. Metal. Rev. 2000, 21, 25 - 48.

(10) Martell, A. E.; Motekaites, R. J. Determination and use of stability constants, 2nd ed.; Wiley-VCH: New York, NY, 1992.

(11) Hutton, A. T.; Linder, P. W. In Encyclopedia of Inorganic Chemistry; 2nd ed.; King, R. B., Ed.; John Wiley \& Sons: New York, NY, 2007.

(12) Dimmock, P. W.; Warwick, P.; Robbins, R. A. Analyst 1995, 120, 21592170.

(13) Calvin, M.; Melchior, N. C. J. Am. Chem. Soc 1948, 70, 3270.

(14) Irving, H.; Williams, R. J. P. J. Chem. Soc. 1953, 3192-3210.

(15) Hancock, R. D.; Martell, A. E. Chem. Rev. 1989, 89, 1875-1914.

(16) Filipovic, I.; Tkalcec, M.; Grabaric, B. S. Inorg. Chem. 1990, 29, 1092.

(17) Hurley, M. A.; Tipping, E. Geochim. Cosmochim. Acta 1992, 56, 3627.

(18) Edwards, J. O.; Pearson, R. G. J. Am. Chem. Soc. 1961, 84, 16.

(19) Pearson, R. G. J. Chem. Educ. 1968, 45, 643-648.

(20) Misono, M.; Saito, Y. Bull. Chem. Soc. Japan 1970, 43, 3680.

(21) Hancock, R. D.; Marsicano, F. Inorg. Chem. 1980, 19, 2709.

(22) Drago, R. S.; Kroeger, M. K. J. Am. Chem. Soc. 1981, 103, 3250.

(23) Hancock, R. D. Analyst 1997, 122, 51R-58R.

(24) Brubaker, G. R.; Johnson, D. W. Coord. Chem. Rev. 1984, 53, 1.

(25) Marques, H. M.; Brown, K. L. Coord. Chem. Rev. 2002, 225, 123-158.

(26) Frenking, G.; Froehlich, N. Chem. Rev. 2000, 100, 717.

(27) Hegarty, D.; Robb, M. A. Mol. Phys. 1979, 38, 1795.

(28) Reiher, M.; Salomon, O.; Hess, B. A. Theor. Chem. Acc. 2001, 107, 1.

(29) Koch, W.; Holthausen, M. C. A Chemist's Guide to Density Functional Theory, 2nd ed.; Wiley-VCH: Weinheim, 2001.

(30) Hancock, R. D.; Bartolotti, L. J. Inorg. Chem. 2005, 44, 7175-7183.

(31) Noodleman, L.; Han, W.-G. J. Biol. Inorg. Chem. 2006, 11, 674-694.

(32) Shultz, N. E.; XZhao, Y.; Truhlar, D. G. J. Chem. Phys. A 2005, 109, 11127-11143.

(33) Erras-Hanauer, H.; Clark, T.; van Eldik, R. Coord. Chem. Rev. 2003, 238239, 233-253.

(34) Díaz, N.; Suárez, D.; Merz, K. M. Chem. Phys. Lett. 2000, 326, 288-292.

(35) Fouqueau, A.; Mer, S.; Casida, M. E.; Daku, L. M. L.; Hauser, A.; Mineva, T.; Neese, F. J. Chem. Phys. 2004, 120, 9473-9486. 
(36) Neese, F. J. Biol. Inorg. Chem. 2006, 11, 702-711.

(37) Zerner, M. C.; Martin, C. H. In Inorganic electronic structure and spectroscopy; Solomon, E. I., Lever, A. B. P., Eds.; Wiley: New York, 1999; Vol. 1; pp 661.

(38) Schaad, D. R. In Handbook of Chiral Chemicals; 2nd ed.; Ager, D., Ed.; CRC Press: Boca Raton, FL, 2005; pp 443-456. 441.

(39) Wong, D. T.; Bymaster, F. P.; Engleman, E. A. Life Sci. 1995, 57, 411-

(40) Kwon, S. J.; Ko, S. Y. Tetrahedron Lett. 2002, 43, 639-641.

(41) Ager, D. J.; Prakash, I.; Schaad, D. R. Chem. Rev. 1996, 96, 835-876.

(42) Cardillo, G.; Tomasini, C. Chem. Soc. Rev. 1996, 25, 117-128.

(43) Noyori, R. Asymmetric Catalysis in Organic Synthesis; Wiley: New York, 1994.

(44) Dabrowiak, J. C. Metals in Medicine; John Wiley \& Sons: Chichester, UK, 2009.

(45) de Sousa, A. S.; Hancock, R. D.; Reibenspies, J. H. J. Chem. Soc., Dalton Trans. 1997, 2831-2836.

(46) Hancock, R. D. In Perspectives in Coordination Chemistry; Williams, A. F.; Floriani, C., Merbach, A. E., Eds.; VCHA and VCH: Basel and Weinheim, 1992; pp 129-151.

(47) de Sousa, A. S.; Croft, G. J. B.; Wagner, C. A.; Michael, J. P.; Hancock, R. D. Inorg. Chem. 1991, 30, 3525-3529.

(48) Hancock, R. D.; de Sousa, A. S.; Walton, G. B.; Reibenspies, J. H. Inorg. Chem. 2007, 46, 4749-4757.

(49) de Sousa, A. S.; Reisinger, S. A.; Fernandes, M. A.; Perry, C. B.;

Varadwaj, P. R.; Marques, H. M. J. Chem. Soc., Dalton Trans. 2009, 10208-10218.

(50) Bader, R. F. Atoms in Molecules: A Quantum Theory; Oxford University Press: Oxford, 1990.

$415-417$

(51) de Sousa, A. S.; Hancock, R. D. J. Chem. Soc., Chem. Commun. 1995,

(52) de Sousa, A. S.; Fernandes, M. A.; Padayachy, K.; Marques, H. M. Inorg. Chem. 2010, 49, 8003-8011.

(53) Hall, J. L.; Dean, W. G.; Pacofsky, E. A. J. Am. Chem. Soc. 1960, 82, 3303-3308.

(54) Martell, A. E.; Smith, R. M.; Motekaites, R. J. NIST Criticially Selected Stability Constants of Metal Complexes, V. 8.0; NIST, Gaithersburg, MD, 2004.

(55) Uwamariya, V. Electrochemical studies of metal-ligand equilibria involving chelatig ligands. M.Sc. Dissertation, University of the Witwatersrand, 2005. 2677.

(56) Xu, X.; Goddard, W. A. Proc. Natl. Acad. Sci. U.S.A. 2004, 101, 2673-

(57) Perdew, J. P.; Burke, K.; Ernzerhof, M. Phys. Rev. Lett. 1996, 77, $3865-$

3868.

(58) Perdew, J. P.; Burke, K.; Ernzerhof, M. Phys. Rev. Lett. 1997, 78, 1396.

(59) Varadwaj, P. R.; Cukrowski, I.; Marques, H. M. J. Mol. Str. (Theochem) 2009, 915, 20-32.

(60) Frisch, M. J.; Trucks, G. W.; Schlegel, H. B.; Scuseria, G. E.; Robb, M. A.; Cheeseman, J. R.; Montgomery, J. J. A.; Vreven, T.; Kudin, K. N.; Burant, J. C.; Millam, J. M.; Iyengar, S. S.; Tomasi, J.; Barone, V.; Mennucci, B.; Cossi, M.; Scalmani, G.; Rega, N.; Petersson, G. A.; Nakatsuji, H.; Hada, M.; Ehara, M.; Toyota, K.; Fukuda, R.; Hasegawa, J.; Ishida, M.; Nakajima, T.; Honda, Y.; Kitao, O.; Nakai, H.; Klene, M.; 
Li, X.; Knox, J. E.; Hratchian, H. P.; Cross, J. B.; Adamo, C.; Jaramillo, J.; Gomperts, R.; Stratmann, R. E.; Yazyev, O.; Austin, A. J.; Cammi, R.; Pomelli, C.; Ochterski, J. W.; Ayala, P. Y.; Morokuma, K.; Voth, G. A.; Salvador, P.; Dannenberg, J. J.; Zakrzewski, V. G.; Dapprich, S.; Daniels, A. D.; Strain, M. C.; Farkas, O.; Malick, D. K.; Rabuck, A. D.; Raghavachari, K.; Foresman, J. B.; Ortiz, J. V.; Cui, Q.; Baboul, A. G.; Clifford, S.; Cioslowski, J.; Stefanov, B. B.; Liu, G.; Liashenko, A.; Piskorz, P.; Komaromi, I.; Martin, R. L.; Fox, D. J.; Keith, T.; Al-Laham, M. A.; Peng, C. Y.; Nanayakkara, A.; Challacombe, M.; Gill, P. M. W.; Johnson, B.; Chen, W.; Wong, M. W.; Gonzalez, C.; Pople, J. A. Gaussian 03, v. 2003, Gaussian Inc.: Pittsburg, PA, 2004.

(61) Dennington, R.; Keith, T.; Millam, J.; Eppinnett, K.; Hovell, W. L.; Gilliland, R. GaussView, v. 3.09, Semichem, Inc.: Shawnee Mission, KS, 2003.

(62) Xu, X.; Goddard, W. A. J. Phys. Chem. A 2004, 108, 2305-2313.

(63) Xu, X.; Zhang, Q.; Muller, R. P.; Goddard, W. A. J. Chem. Phys. 2005, 122,014105 .

(64) Lee, C.; Yang, W.; Parr, R. G. Phys. Rev. B 1988, 37, 785-789.

(65) van Mourik, T.; Gdanitz, R. J. J. Chem. Phys. 2002, 116, 9620-9623.

(66) Sinnokrot, M. O.; Sherrill, C. D. J. Phys Chem. A 2006, 110, 10656-

10668.

(67) Hyla-Kryspin, I.; Haufe, G.; Grimme, S. Chem. Eur. J. 2004, 10, 3411-

3422.

(68) Hammer, B.; Hansen, L. B.; Nørskov, J. K. Phys. Rev. B 1999, 59, 7413-

7421.

(69) Zhang, Y.; Yang, W. Phys. Rev. Lett. 1998, 80, 890-890.

(70) Maximoff, S. N.; Peralta, J. E.; Barone, V.; Scuseria, G. E. J.

Chem.Theory Comput. 2005, 1, 541-545

(71) Onsager, L. J. Am. Chem. Soc. 1936, 58, 1486-1493.

(72) Tapia, O.; Goscinski, O. Mol. Phys. 1975, 29, 1653-1662.

(73) Miertus, S.; Scrocco, E.; Tomasi, J. Chem. Phys. 1981, 55, 117-129

(74) Tomasi, J.; Persico, M. Chem. Rev. 1994, 94, 2027-2094.

(75) Cramer, C. J.; Truhlar, D. G. Chem. Rev. 1999, 99, 2161-2200.

(76) Chipman, D. M. J. Phys. Chem. A. 2002, 106, 7413-7422.

(77) Zhan, C.-G.; Bentley, J.; Chipman, D. M. J. Chem. Phys. 1998, 108, 177-

192.

(78) Klamt, A.; Schüürmann, G. J. Chem. Soc., Perkin Trans. 2 1993, 799-805.

(79) Andzelm, J.; Kölmel, C.; Klamt, A. J. Chem. Phys. 1995, 103, 9312-9320.

(80) Barone, V.; Cossi, M. J. Phys. Chem. A 1998, 102, 1995-2001.

(81) Cossi, M.; Barone, V. J. Chem. Phys. 1998, 109 6246-6254. $669-681$

(82) Cossi, M.; Rega, N.; Scalmani, G.; Barone, V. J. Comput. Chem. 2003, 24,

(83) McLean, A. D.; Chandler, G. S. J. Chem. Phys. 1980, 72, 5639-5648.

(84) Krishnan, R.; Binkley, J. S.; Seeger, R.; Pople, J. A. J. Chem. Phys. 1980, $72,650-654$.

(85) Keith, T. A. AIMAll, v. 08.05.04, http://aim.tkgristmill.com, 2008.

(86) Biegler-König, F. W.; Schönbohm, J.; Bayles, D. AIM2000, v. 1, http://www.gauss.fh-bielefeld.de/aim2000

(87) Biegler-König, F. W.; Schönbohm, J.; Bayles, D. J. Comp. Chem. 2001, $22,545-559$.

(88) Boys, S. F.; Bernardi, F. Mol. Phys. 1970, 19 553-566.

(89) Varadwaj, P. R.; Cukrowski, I.; Marques, H. M. J. Mol. Str. (Theochem) 2009, 902, 21-32. 
(90) Wiberg, K. B. Angew. Chem., Int. Ed. Engl. 1986, 25, 312-322.

(91) Wiberg, K. B.; Bader, R. F. W.; Lau, C. D. H. J. Am. Chem. Soc. 1987, 109, 1001-1012.

(92) Wiberg, K. B.; Bader, R. F. W.; Lau, C. D. H. J. Am. Chem. Soc. 1987, 109, 985-1001.

(93) Feng, Y.; Liu, L.; Wang, J.-T.; Zhao, S.-W.; Q-X., G. J. Org. Chem. 2004, 69, 3129-3138. 440-447.

(94) Vila, A.; de la Puente, E.; Mosquera, R. A. Chem. Phys. Lett. 2005, 405,

(95) Zhao, C.-Y. Z., Y.; You, X.-Z. J. Phys. Chem. A 1997, 101, 5174-5182.

(96) Cukrowski, I.; Matta, C. F. Chem. Phys. Lett. 2010, 499, 66-69.

(97) Matta, C. F.; Hernandez-Trujillo, J.; Tang, T.-H.; Bader, R. F. W. Chem. Eur. J. 2003, 9, 1940-1951.

(98) Poater, J.; Sola, M.; Bickelhaupt, F. M. Chem. Eur. J. 2006, 12, 2889-

2895.

(99) Bader, R. F. W. Chem. Eur. J. 2006, 12, 2896-2901.

(100) Martín Pendás, A.; Francisco, E.; Blanco, M. A.; Gatti, C. Chem. Eur. J. 2007, 13, 9362-9371.

(101) Espinosa, E.; Molins, E.; Lecomte, C. Chem. Phys. Lett. 1998, 285, 170173. 315-347.

(102) Hancock, R. D.; Maumela, H.; de Sousa, A. S. Coord. Chem. Rev. 1996,

(103) Tanase, T.; Mano, K.; Yamamoto, Y. Inorg. Chem. 1993, 32, 3995-4003.

(104) Xie, Y.; Jiang, H.; Yu, M.; Du, C.; Liu, Q.; Xu, X.; Zhu, Y. J. Mol. Str. 2002, 608, 169-173.

(105) Xu, Q.; Kbokhar, A. R.; Bear, J. L. Inorg. Chim. Acta 1990, 178, 107-111. 349-355.

(106) Galanski, M.; Berger, M.; Keppler, B. K. Metal Based Drugs 2000, 7,

(107) Varadwaj, P. R.; Cukrowski, I.; Marques, H. M. J. Phys. Chem. A 2008, $112,10657-10666$.

(108) Varadwaj, P. R.; Marques, H. M. Phys. Chem. Chem. Phys. 2010, 12, 2126-2138.

(109) Bader, R. F. W.; Essén, H. J. Chem. Phys. 1984, 80, 1943-1960.

(110) Cramer, D.; Kraka, E. Angew. Chem. Int. Ed. Engl. 1984, 23, 627-628.

(111) Cramer, D.; Kraka, E. Croat. Chem. Acta 1984, 57, 1259-1281.

(112) Bone, R. G. A.; Bader, R. F. W. J. Phys. Chem. 1996, 100, 10892-10911.

(113) Bobrov, M. F.; Popova, G. V.; Tsirelson, V. G. Russ. J. Phys. Chem. 2006, $80,584-590$.

(114) Macchi, P.; Sironi, A. Coord. Chem. Rev. 2003, 238-239, 383-412.

(115) Espinosa, E.; Alkorta, I.; Elguero, J.; Molins, E. J. Chem. Phys. 2002, 117, $5529-5542$.

(116) Jenkins, S.; Morrison, I. Chem. Phys. Lett. 2000, 317, 97-102.

(117) Farrugia, L. J.; Frampton, C. S.; Howard, J. A. K.; Mallinson, P. R.; Peacock, R. D.; Smith, G. T.; Stewart, B. Acta Cryst., Sec. B 2006, B62, $236-244$.

(118) Cukrowski, I.; Govender, K. K. Inorg. Chem. 2010, 49, 6931-6941.

(119) de Sousa, A. S.; Hlam, Z.; Fernandes, M. A.; Marques, H. M. Acta Crystallogr. Sec. C. 2010, C66, o229-0232.

(120) de Sousa, A. S.; Hlam, Z.; Fernandes, M. A.; Marques, H. M. Acta Crystallogr. Sec. C. 2010, C66, o553-0556. 